\title{
-Opposite Responses of the Indian Ocean to the Thermal Forcing of the Tibetan Plateau before and after the Onset of the South Asian Monsoon $\mathcal{O}$
}

\author{
YU ZHAO, ${ }^{\mathrm{a}, \mathrm{b}, \mathrm{c}}$ ANMIN DUAN, ${ }^{\mathrm{b}, \mathrm{c}}$ AND GUOXIONG WU ${ }^{\mathrm{b}, \mathrm{c}}$ \\ ${ }^{a}$ School of Geoscience and Technology, Zhengzhou University, Zhengzhou, China \\ ${ }^{\mathrm{b}}$ State Key Laboratory of Numerical Modelling for Atmospheric Sciences and Geophysical Fluid Dynamics (LASG), Institute of \\ Atmospheric Physics (IAP), Chinese Academy of Sciences (CAS), Beijing, China \\ ${ }^{\mathrm{c}}$ University of Chinese Academy of Sciences, Beijing, China
}

(Manuscript received 19 December 2020, in final form 30 June 2021)

\begin{abstract}
The atmospheric circulation changes dramatically over a few days before and after the onset of the South Asian monsoon in spring. It is accompanied by the annual maximum surface heating over the Tibetan Plateau. We conducted two sets of experiments with a coupled general circulation model to compare the response of atmospheric circulation and wind-driven circulation in the Indian Ocean to the thermal forcing of the Tibetan Plateau before and after the monsoon onset. The results show that the Tibetan Plateau's thermal forcing modulates the sea surface temperature (SST) of the Indian Ocean and the meridional circulation in the upper ocean with opposite effects during these two stages. The thermal forcing of the Tibetan Plateau always induces a southwesterly response over the northern Indian Ocean and weakens the northeasterly background circulation before the monsoon onset. Subsequently, windevaporation feedback results in a warming SST response. Meanwhile, the oceanic meridional circulation shows offshore upwellings in the north and southward transport in the upper layer crossing the equator, sinking near $15^{\circ} \mathrm{S}$. After the monsoon onset, the thermal forcing of the Tibetan Plateau accelerates the background southwesterly and introduces a cooling response to the Indian Ocean SST. The response of oceanic meridional overturning circulation is limited to the north of the equator due to the location and structural evolution of the climatological local Hadley circulation. With an acceleration of the local Walker circulation, the underlying zonal currents also show corresponding changes, including a westerly drift along the equator, downwelling near Indonesia, offshore upwelling near Somalia, and a westward undercurrent.
\end{abstract}

KEYWORDS: Indian Ocean; Air-sea interaction; Thermodynamics; Numerical analysis/modeling

\section{Introduction}

Both air-sea interactions and thermal forcing by the Tibetan Plateau are crucial in the Asian summer monsoon system (Wang 2006), but the connection between them has not yet been explored. The Asian summer monsoon is thought to be the most complex monsoon system and is insufficiently understood (Wang 2006; IPCC 2013). One reason for this complexity is air-sea interactions, which involve many nonlinear processes (Li et al. 2001; Wang et al. 2005). The seasonal march of the sea surface temperature (SST) changes the boundary conditions crucial to the vortex generation that marks the onset of the monsoon and the release of latent heat (Wu et al. 2012). The monsoon also shows strong feedback to the ocean (Lighthill 1969; Leetmaa 1972; Schott et al. 2009).

Air-sea interactions in the Indian Ocean are involved in many important climate processes, including the capacitor

๑ Denotes content that is immediately available upon publication as open access.

Supplemental information related to this paper is available at the Journals Online website: https://doi.org/10.1175/JCLI-D-200982.s1.

Corresponding author: Anmin Duan, amduan@lasg.iap.ac.cn effect of the Indian Ocean SST, which prolongs the influence of El Niño-South Oscillation (ENSO) on the Asian summer monsoon (Klein et al. 1999; Xie et al. 2002; Yang et al. 2007; Li et al. 2008; Du et al. 2009). The SST in the Indian Ocean can also exert a significant influence on the western North Pacific subtropical high and the South Asian high, modulating the precipitation over East Asia (Wu et al. 2010; Liu and Duan 2017).

The Tibetan Plateau has the highest topography on Earth, and its mechanical and thermal effects have been reported in many studies (Yeh 1950; Wu 1984; Ye and Wu 1998; Boos and Kuang 2010, 2013; Wu et al. 2012). The total atmospheric heat source over the Tibetan Plateau depends mainly on the surface sensible heating in spring and the release of latent heat in summer, both of which play a unique part in shaping the Asian climate (Zhao and Chen 2001; Wu et al. 2007). The Tibetan Plateau is also known to influence atmospheric circulation in the middle and high latitudes by Rossby waves (Huang 1985; Broccoli and Manabe 1992; Rodwell and Hoskins 2001). The related SST and meridional overturning circulation in the northern Pacific and Atlantic Oceans are thought to be related to the thermal forcing of the Tibetan Plateau (Fallah et al. 2015; Yang and Wen 2020; Wen and Yang 2020).

The atmospheric circulation over the Indian Ocean is highly correlated with the thermal conditions of the Tibetan Plateau (Wu et al. 2012; Ji et al. 2018), but the influence on the oceans is not well understood yet. Ye and Gao (1979) showed that the heat source of the Tibetan Plateau is closely related to the local 
Hadley circulation over the Indian Ocean and has a teleconnection with the Southern Hemisphere. Hu and Duan (2015) showed a close relationship between the Indian Ocean SST and the Tibetan Plateau heat source when comparing their contribution to the East Asian summer monsoon. Although existing studies have shown that the Indian Ocean SST may affect the Tibetan Plateau heat source (Chen and You 2017; Zhao et al. 2018), the potential influence of the Tibetan Plateau heat source on the Indian Ocean has attracted less attention. Considering that surface heating over the Tibetan Plateau can significantly influence the surrounding atmosphere, such as by acting as a heat pump (Wu et al. 2007), and that the Indian Ocean is the nearest ocean, known for its monsoonal character (Cadet and Diehl 1984; Xie et al. 2009), the Indian Ocean, under certain circumstances, might also be influenced by the thermal forcing of the Tibetan Plateau.

Coupled general circulation models (CGCMs) are widely used in exploring the relationship between topography and complicated monsoon system. Kitoh (2004) suggested that topography can significantly influence both global SSTs and the Asian monsoon. Abe et al. (2013) focused on the effects of the topography of the Tibetan Plateau and found that the onset date of the South Asian monsoon was delayed by 10-15 days as the Indian Ocean SST was affected, although they did not consider the specific response of the wind-driven circulation. Baldwin et al. (2019) eliminated the Asian terrain in a CGCM and found that the SST in the northwest Pacific Ocean and the Arabian Sea upwellings showed significant changes. These results provide references for paleoclimate advances, while more thermodynamic studies are needed to understand the modern climate.

Wang et al. (2018) discussed the relationship between thermal forcing of the Tibetan Plateau in summer and air-sea interactions in the Indian Ocean and found that the SST in the northern Indian Ocean is cooled by increased southwesterly winds, which suppress the convection activities of the surrounding monsoon. By comparing the results of an atmospheric general circulation model and the CGCM, He et al. (2018) concluded that the air-sea interactions cancel out the direct influence of the Tibetan-Iranian Plateau on the surrounding atmosphere. In sum, CGCM is a powerful tool for exploring the relationship between the Tibetan Plateau and air-sea interactions over the Indian Ocean, which is crucial in understanding the Asian climate.

Despite these efforts, the modulation of the thermal forcing of the Tibetan Plateau on the Indian Ocean is still unclear. When exploring the related air-sea interaction processes, more attention has been given to their potential role in feeding back to the monsoon while omitting the related changes in the winddriven circulation in the ocean and the overall meridional circulation. In addition, although most existing studies focus on summer, more attention should be given to the spring months because the surface of the Tibetan Plateau heats the atmosphere most strongly during this season and can significantly affect the surrounding atmosphere and air-sea interactions. This can be seen from our recent work (Zhao et al. 2019), in which we discuss the instantaneous response of the Indian Ocean SST and Ekman transport to the thermal forcing of the
Tibetan Plateau in late spring. In our current research, rather than modifying Tibetan Plateau heating into weak and strong years based on interannual variability, we conducted ideal experiments with a completely closed heating process over the Tibetan Plateau to focus purely on the part it plays in the climate system. The situations in early and late spring are discussed separately because they represent two different stages of the South Asian monsoon.

The rest of the paper is organized as follows. Section 2 introduces the data and numerical models used in this study and describes the experimental design. Section 3 presents the changes in the atmospheric and oceanic circulation in the Indian Ocean due to thermal forcing of the Tibetan Plateau in the CGCM and analyzes the possible mechanisms according to the model results. Section 4 presents a summary of the results, the potential limitations of the present work, and avenues for future research.

\section{Methods}

\section{a. Data}

We used meteorological observations collected by the China Meteorological Administration from 73 stations on the Tibetan Plateau to estimate the surface sensible heat, including the air temperature at $2 \mathrm{~m}$, the ground surface temperature, and the wind speed at $10 \mathrm{~m}$. We applied quality control procedures to eliminate erroneous data and ensure homogeneity (Duan et al. 2011).

Following Duan and $\mathrm{Wu}$ (2008), the sensible heat flux over the Tibetan Plateau is estimated using the bulk aerodynamic method:

$$
\text { sensible heat }=C_{p} \rho C_{D H} V_{0}\left(T_{s}-T_{a}\right) \text {, }
$$

where $C_{p}$ is the specific heat of dry air at a constant pressure and $\rho$ is the density of air; $C_{D H}$ is the drag coefficient for heat and was taken as $C_{D H}=4 \times 10^{-3}\left(\mathrm{Li}\right.$ and Yanai 1996), $V_{0}$ is the mean wind speed measured at $10 \mathrm{~m}$ above the ground surface, and $T_{s}-T_{a}$ is the difference between the ground surface temperature and the air temperature.

We also used the monthly SST from the Hadley Center Global Sea Ice and Sea Surface Temperature dataset, version 1.1 (Rayner et al. 2003) with a resolution of $1.0^{\circ} \times 1.0^{\circ}$ and the monthly circulation data from the Japanese 55-year Reanalysis (JRA-55) project conducted by the Japan Meteorological Agency (Ebita et al. 2011; Kobayashi et al. 2015) with a resolution of $1.25^{\circ} \times 1.25^{\circ}$. These datasets were used to assess the model results, and all covered the period 1980-2014.

\section{b. Models}

We used the FGOALS-s2 (Flexible Global Ocean-AtmosphereLand System Model, spectral version 2) CGCM. FGOALS-s2 is published by the State Key Laboratory of Numerical Modeling for Atmospheric Sciences and Geophysical Fluid Dynamics/Institute of Atmospheric Physics (LASG/IAP) and consists of four individual components: SAMIL2 (the Spectral Atmospheric Model developed at the LASG/IAP, version 2; Wu et al. 1996; Bao et al. 2010); LICOM2 (the LASG/IAP Climate System Ocean Model, version 2; Liu et al. 2014); CLM3 (the Community Land Model, version 3; Oleson et al. 2004); and 
CSIM5 (the Community Sea Ice Model, version 5; Briegleb et al. 2004). The fluxes were exchanged between these components using version 6 of the coupler module from the National Center for Atmospheric Research (Collins et al. 2006). FGOALS-s2 captures the precipitation trend in the South Asian monsoon area and reproduces the stepwise meridional displacement of the monsoon rainband (Bao et al. 2013). Generally, FGOALS-s2 shows sufficient performance in the Asian monsoon area.

\section{c. Experiments}

We conducted two experiments to investigate the modulation of the thermal forcing of the Tibetan Plateau on the atmospheric and oceanic circulation over the Indian Ocean in spring. In the first experiment (CTRL), we integrated the CGCM model for 130 years and analyzed the results for the last 20 years. In the second experiment (NoTPSH), the surface was not allowed to heat the atmosphere over the area of the Tibetan Plateau $\left(10^{\circ}-45^{\circ} \mathrm{N}, 70^{\circ}-110^{\circ} \mathrm{E}\right.$; elevation $>500 \mathrm{~m}$; green area in Fig. 2a) in March-May. The CGCM model was integrated for 30 years from the 100th year, and the last 20 years (during which the Indian Ocean is well adjusted to the forcing, as shown in Fig. S1 in the online supplemental material) were analyzed. The experiment did not modify the surface temperature or the sensible heat directly to maintain the surface energy balance process. Instead, vertical diffusion was changed to indirectly shut down surface heating over the Tibetan Plateau, following Wu et al. (2007). In other words, the land surface module loses heat as usual, but the atmosphere does not obtain these heat fluxes from surface. Technically, we modified the process of land surface heating of the atmosphere by setting the parameter $k$ to zero in the $k \partial \theta / \partial z$ term, leaving $\partial \theta / \partial z$ to vary normally. This is reasonable because the sensible heat in this model is obtained by integrating the vertical diffusion in the atmosphere column. This method is the same as that used in Wu et al. (2012) and He et al. (2015). Because this modification was only carried out in the atmospheric module, it did not directly affect the integration of the land surface processes, and the impact on the energy balance was limited. Therefore, the model can be integrated stably for a long time without being heated by the Tibetan Plateau and provides a convenient way to observe changes in the atmosphere and oceans. The impacts of Tibetan Plateau thermal forcing on the atmosphere and ocean circulation in spring can be reflected by the difference in CTRL and NoTPSH. Student's $t$ test was used to assess the statistical significance of the difference.

\section{Results}

\section{a. Thermal characteristics of the Tibetan Plateau}

The surface heating of the Tibetan Plateau can effectively and directly drive the atmosphere in spring. With the rainy season's arrival, the release of the latent heat of condensation gradually supersedes the sensible heat (Zhao and Chen 2001; Zhao et al. 2018). This means that the composition of the Tibetan Plateau heat source changes, and the thermodynamic mechanisms affecting the atmosphere also change. We focused on modulating the atmosphere and the Indian Ocean by Tibetan Plateau sensible heat in March-May (MAM). This is not simple conformity with the traditional definition of spring in the astronomical calendar but is based on observing the seasonal evolution of the surface heating of the Tibetan Plateau, which shows high persistence in MAM. According to the 12-month lead-lag correlation diagram of the surface sensible flux of the Tibetan Plateau averaged over the 73 stations (Fig. 1b), March, April, and May are the three consecutive months with the closest relationship, in which the lead-lag correlation between any two months is $>0.5$. Although the surface sensible flux in February shows a strong correlation with that in March (reaching 0.5), its correlation with the surface sensible flux in April and May is significantly decreased, indicating more asynchronization in their evolution. Previous studies have shown that when the composition of the heat source changes in June, the latent heat of condensation supersedes the sensible heat to become the dominant component of the total heat source over the Tibetan Plateau (Zhao and Chen 2001; Zhao et al. 2018). Because the mechanism of the Tibetan Plateau heat source affecting the atmosphere has changed, it is not appropriate to include June in the same analysis.

The surface sensible flux of the Tibetan Plateau also has the highest value in these three months (Fig. 1a) and is the dominant component of the Tibetan Plateau heat source. Although both the Tibetan Plateau and the Indian Ocean can be generalized in the Asian monsoon area, using the traditional calendar-defined spring season for South Asia may overlook some important details because the circulation changes significantly in this region from March to May. We, therefore, divide spring into two representative stages when discussing the relevant response in South Asia and the tropical Indian Ocean.

The model results from the CTRL experiment successfully captured some features of sensible heat flux over the Tibetan Plateau in spring (Fig. S2). The sensible heat flux is stronger in the central plateau than in the east during spring. It is also stronger in May than in March. However, the overall strength is weaker than that in the observation (Fig. S2g). Considering that we are discussing the existence or nonexistence of sensible heat flux over the Tibetan Plateau in this study, rather than its strength, this error should be acceptable.

\section{b. General atmospheric circulation and air-sea interface}

The heating of the Tibetan Plateau can excite strong circulation anomalies in spring and can therefore be referred to as a strong thermal forcing. Before discussing the changes in the ocean, we need to consider atmospheric circulation. These results are consistent with the thermal adaption theory described in Wu et al. (1997), Wu and Liu (2000), Duan and Wu (2005), and $\mathrm{Wu}$ et al. (2016). The atmospheric response to the Tibetan Plateau surface sensible heat flux generates anticyclonic circulation in the upper level (Fig. S3a) and cyclonic circulation in the lower level (Fig. S3b). Because the Tibetan Plateau is located on the eastern Eurasian continent, the ascent induced by the Tibetan Plateau is in phase with the ascent produced by continental-scale thermal forcing ( $\mathrm{Wu}$ and Liu 2003; Wu et al. 2009); consequently, the strongest monsoon and largest deserts form over the Afro-Eurasian continent (Rodwell and Hoskins 2001; Duan and Wu 2005). 
(a)

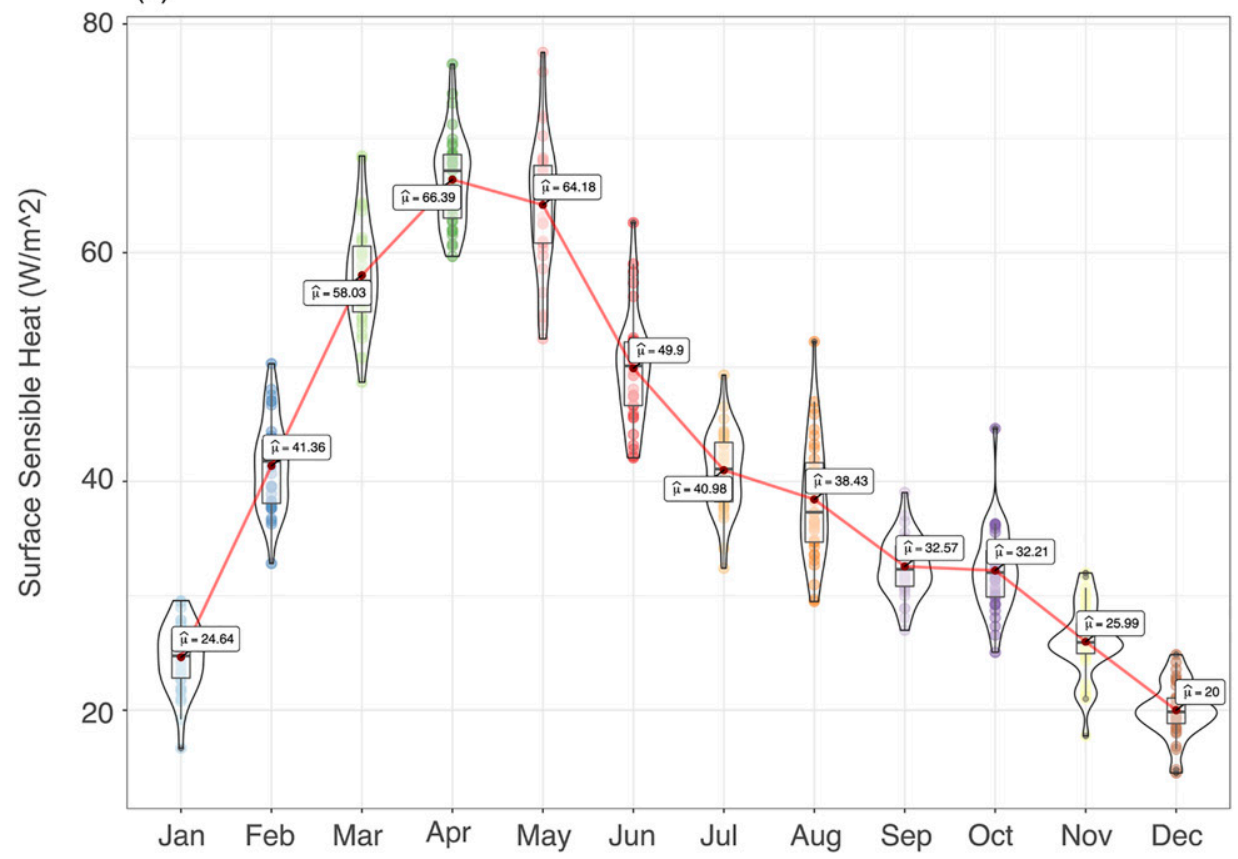

(b)

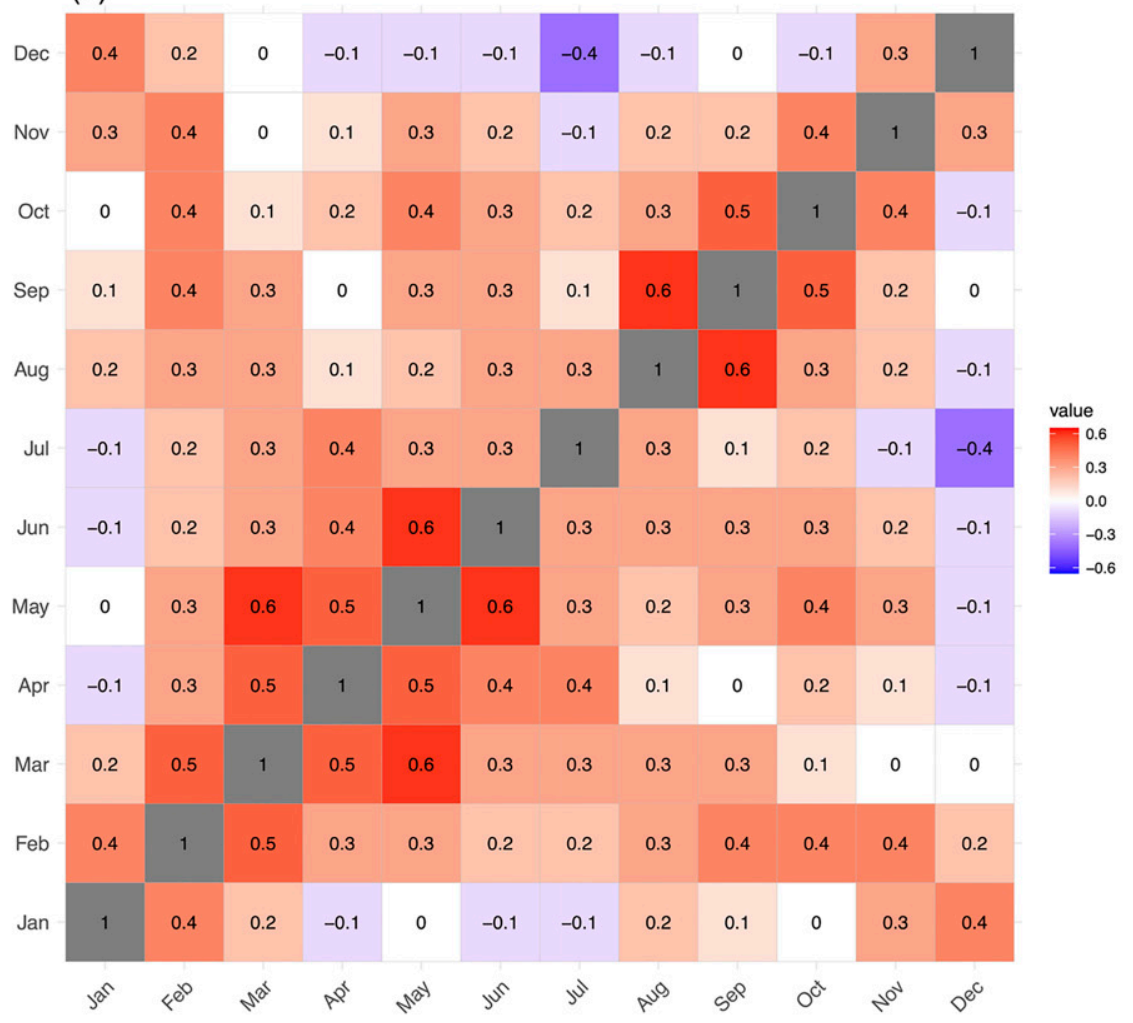

FIG. 1. (a) Box/violin plot of monthly Tibetan Plateau sensible heat flux from 1980 to 2014. The mean value in each month (red dot) is connected by a red line. The 25 th percentile, median (50th percentile), and 75th percentile are shown by the box, with the addition of a rotated kernel density on each side. (b) Lead-lag autocorrelation matrix of monthly TPSH from 1980 to 2014. 

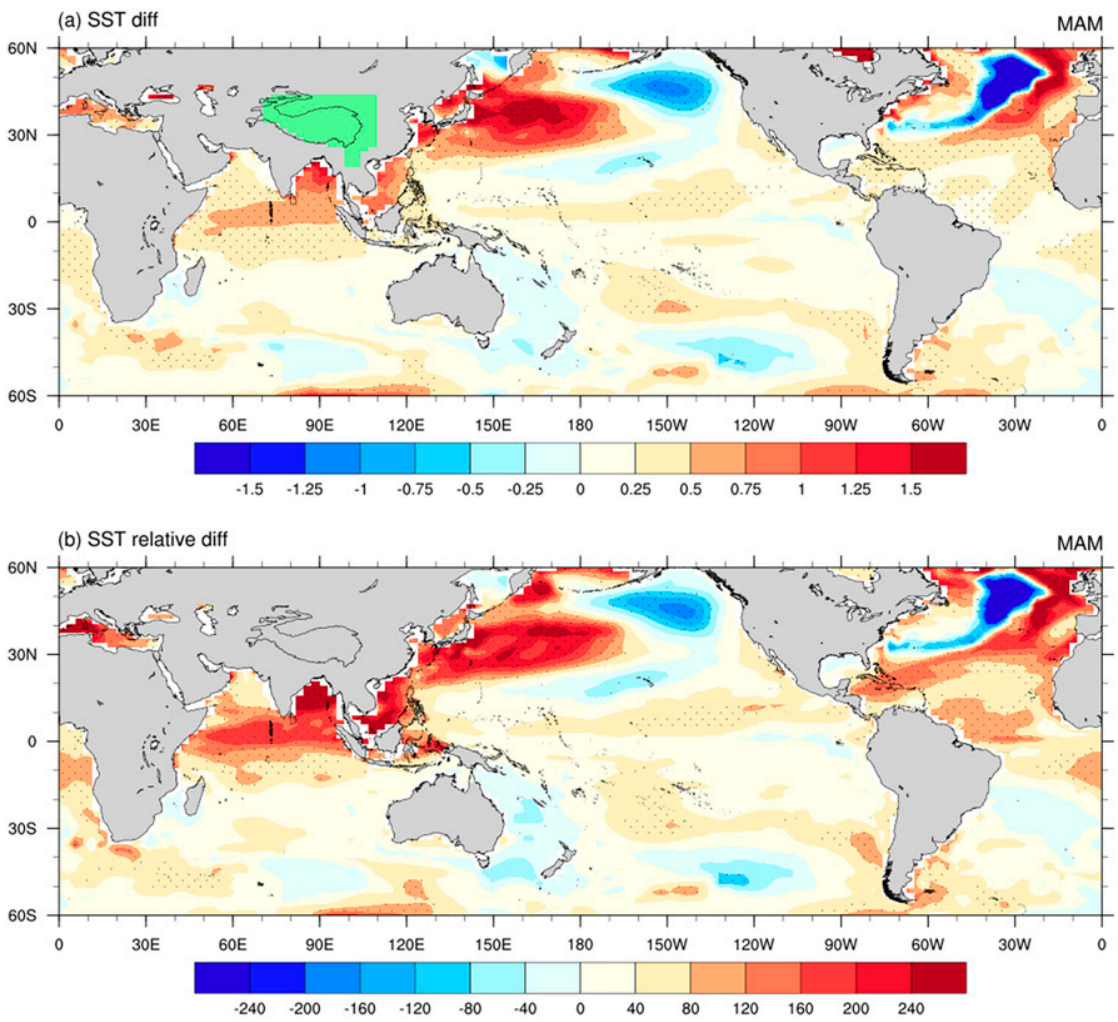

FIG. 2. (a) SST (shading; ${ }^{\circ} \mathrm{C}$ ) changes due to Tibetan Plateau thermal forcing in MAM according to CTRL and NoTPSH experiments. (b) Relative changing rate of (a) to in situ interannual SST standard deviation (shading; \%). Dotted areas indicate statistical significance at the $95 \%$ confidence level according to the two-sided $t$ test. The green area indicates the area where the sensible heat flux is modified in the NoTPSH experiment.

Specifically, the lower tropospheric circulation response to the thermal forcing of the Tibetan Plateau spreads throughout the Northern Hemisphere and, in particular, over the tropical Indian Ocean and northwestern Pacific (Fig. S3b). The response can be summarized as a significant near-surface anomalous cyclonic circulation around the Tibetan Plateau on the Asian continent, corresponding to westerly winds in the Indian Peninsula and the northern Indian Ocean and southerly winds in southern China. From the Sverdrup balance, the relationship between vertical velocity and wind shear can be simplified as $w \propto-(\beta \partial v / f \partial z)$. The heating-induced vertical wind shear anomalies determine that ascent should develop on the east and descent should develop on the west of the heating region. Besides, the descent area in the western monsoon region is also thought to be induced by background westerlies along the slanted isentropes associated with warm anomalies (Rodwell and Hoskins 1996). In addition, cyclonic circulation at lower levels brings abundant vapor to the Indo-China Peninsula and southern China, which enhances local precipitation (Wang et al. 2014; Wu et al. 2015; Liu and Duan 2017). In contrast, the northerlies on the western side of the Tibetan Plateau at the lower level bring cold and dry air from the continent, so reduced precipitation is observed west of the Indian Peninsula, including the Arabian Sea, the Middle East, and eastern Africa (Rodwell and Hoskins 2001; Zhao et al. 2012; Liu et al. 2020). In sum, both vertical motion and water vapor conditions support the precipitation response pattern of "wet in the east and dry in the west."

These significant large-scale changes in atmospheric circulation can affect air-sea interactions and the SST globally. The changes in the SST of the Indian Ocean are much weaker than the significant response of the SST in the mid- to high latitudes of the Northern Hemisphere (i.e., in the North Pacific and North Atlantic Oceans) (Fig. 2a) but pass the $95 \%$ confidence level using a two-sided $t$ test (Fig. 2a). It is well known that the SST in the middle and high latitudes has a large variability as a result of the amplitude of the solar zenith angle and is driven by the rapidly changing atmosphere (Cayan 1992). By contrast, the tropical SST is relatively stable, with a standard deviation of $0.5 \mathrm{~K}$ in the equatorial Indian Ocean (Hu and Duan 2015). To evaluate the adaptive relative changes, the in situ interannual SST standard deviation is calculated as a reference. The relative changing rate shows that the SST response in the Indian Ocean exhibits an equivalent proportion as that in the North Pacific and North Atlantic (Fig. 2b).

The oceanic adjustment caused by the Tibetan Plateau's thermal forcing in spring also occurs throughout the following three seasons (Figs. 3a-d). The SST warming response is strongest in boreal spring (Fig. 3a), with a positive center located in the Bay of Bengal and stronger southwesterly winds 


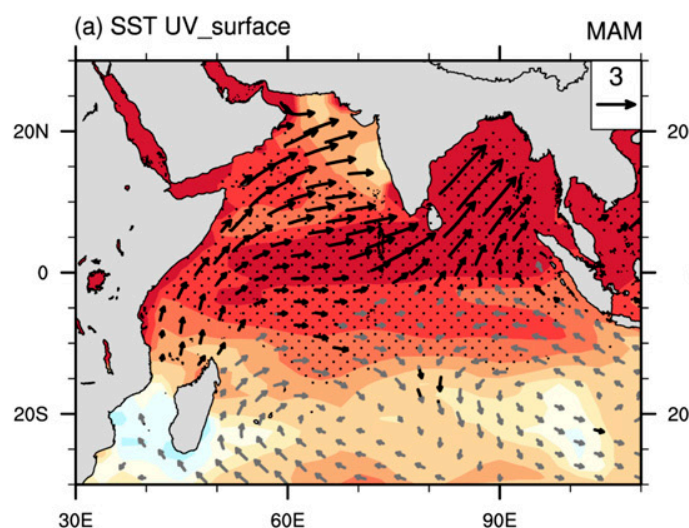

(b) SST UV_surface

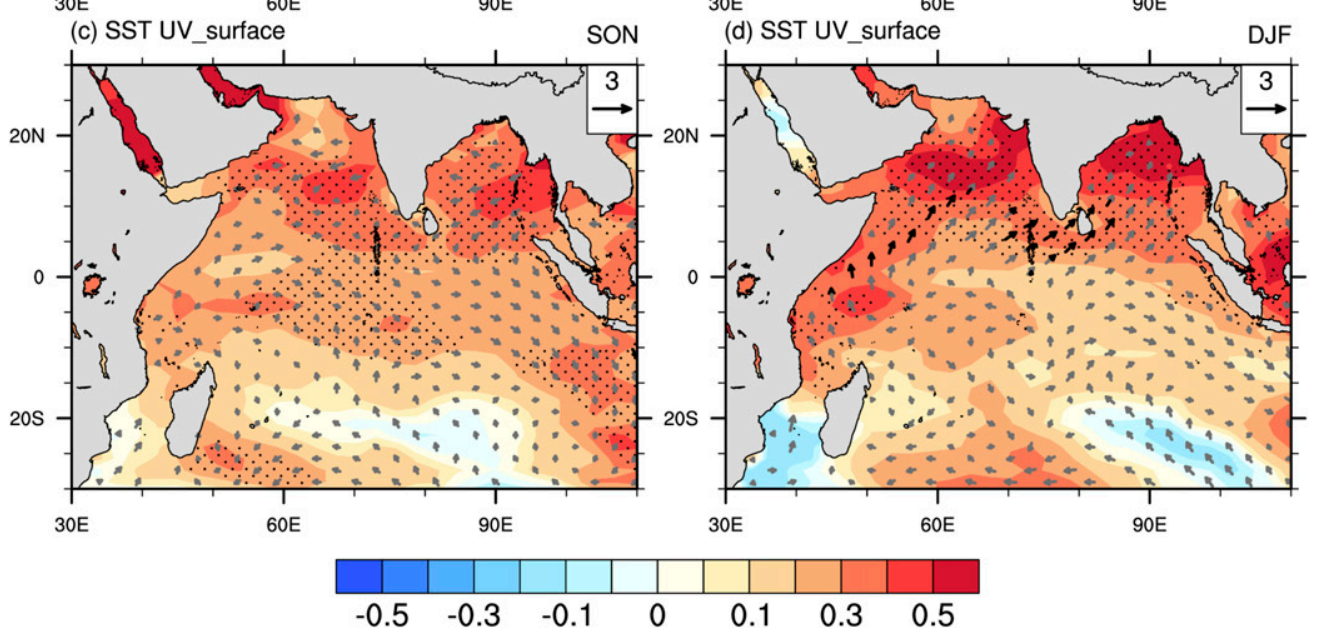

(e)

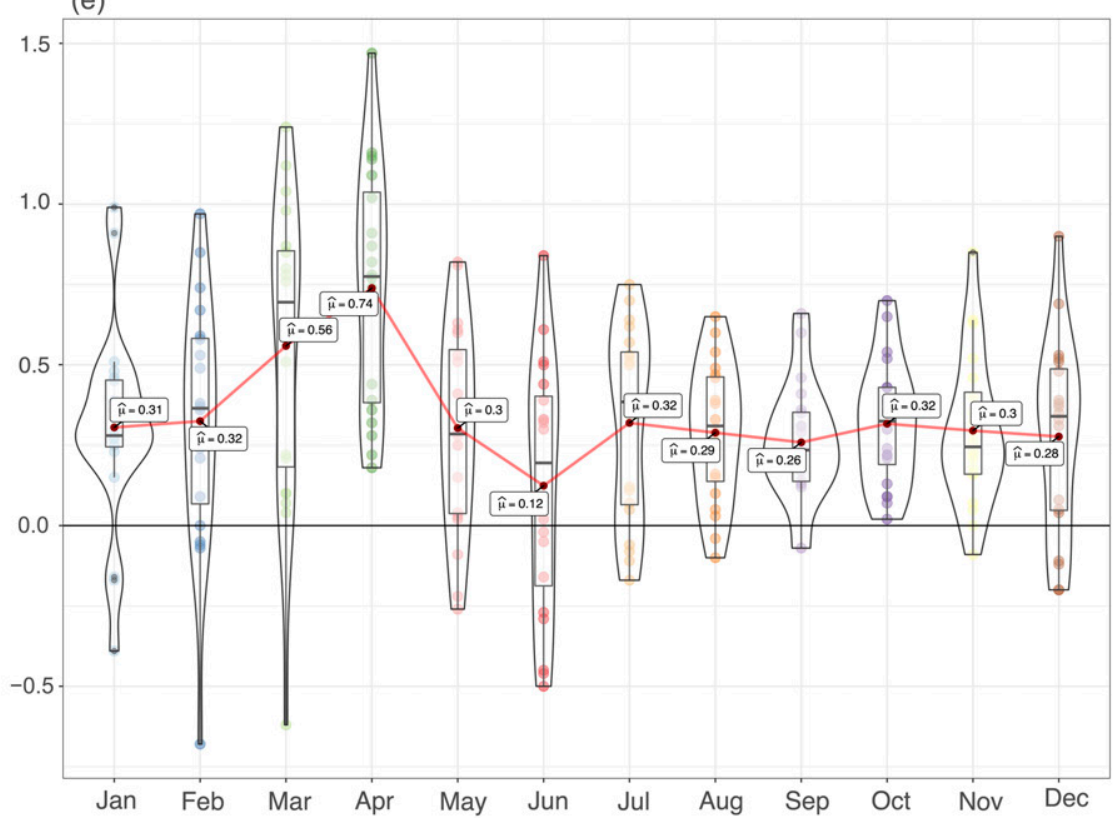

FIG. 3. SST (shading; gpm) and surface wind (vectors; $\mathrm{m} \mathrm{s}^{-1}$ ) changes due to Tibetan Plateau thermal forcing in (a) MAM, (b) JJA, (c) SON, and (d) DJF according to the CTRL and NoTPSH experiments. Dotted areas and black vectors indicate statistical significance at the $95 \%$ confidence level according to the two-sided $t$ test. (e) Box/violin diagram of the area-averaged SST changes over the tropical Indian Ocean $\left(10^{\circ} \mathrm{S}-20^{\circ} \mathrm{N}\right.$, $30^{\circ}-100^{\circ} \mathrm{E}$ ) in each month according to the CTRL and NoTPSH experiments. 

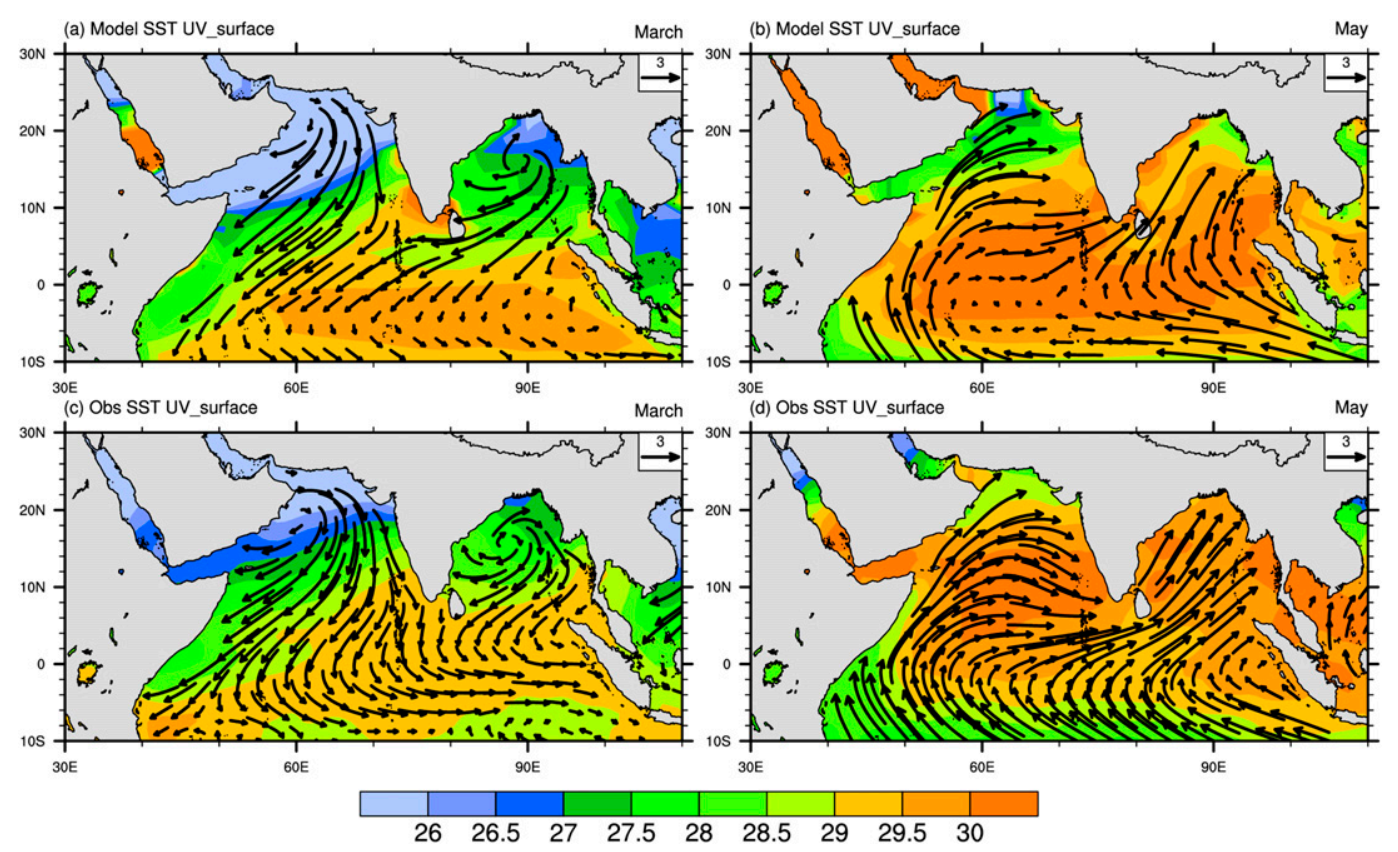

FIG. 4. Climatological mean SST (shading; ${ }^{\circ} \mathrm{C}$ ) and surface wind (vectors; $\mathrm{m} \mathrm{s}^{-1}$ ) in March in (a) CTRL experiments and (c) HadISST/JRA-55 datasets. (b),(d) As in (a) and (c), but in May.

over the entire north Indian Ocean. However, the warm SST response in summer, autumn, and winter is not accompanied by sea surface winds (Figs. 3b-d). This suggests that the significant warming in the Indian Ocean results from changes in the air-sea interaction and atmospheric circulation anomalies caused by the thermal forcing of the Tibetan Plateau in spring. In other seasons, warming may be a continuation of sea temperature warming in the springtime, as seawater has strong thermal inertia (Meehl 1987).

By observing the monthly evolution of the area-averaged SST response of the tropical Indian Ocean $\left(10^{\circ} \mathrm{S}-20^{\circ} \mathrm{N}, 30^{\circ}-\right.$ $100^{\circ} \mathrm{E}$ ), we find that the mean value remained positive and $>0.2 \mathrm{~K}$ and passed the $95 \% t$ test in all months except June (Fig. 3e), which is nonnegligible compared with the overall $0.5-\mathrm{K}$ interannual variability (Hu and Duan 2015). The response of the Indian Ocean SST increases in March, peaks in April, and then decreases rapidly in May, showing a low latency as the Tibetan Plateau is modified only in spring. The SST continues to decrease in June to a minimum value, followed by a $0.3-\mathrm{K}$ warming in the following months. Thus, the thermal forcing of the Tibetan Plateau has an overall warming effect on the climatological state of the Indian Ocean SST.

We investigated why the Indian Ocean SST shows an opposite tendency in March and May. We first considered the wind-evaporation process. As a prerequisite, the CGCM reasonably reproduced the considerable difference in the background winds between March and May (Fig. 4). In March, before the monsoon's onset, northeasterly winds prevail over the Indian Ocean, but these reverse to southwesterly winds in May. The warm center of the SST marches from the equatorial Indian Ocean to the northern Indian Ocean as the point of vertical incidence of sunlight moves northward. These results are consistent with the climatological state in the JRA-55 and HadISST datasets (Figs. 4c,d). The onset of the South Asian summer monsoon is usually marked by the onset of the summer monsoon in the Bay of Bengal at the end of April or the beginning of May (Mao and Wu 2007). Within a few days, the wind direction in South Asia changes dramatically. March and May generally represent the stages before and after the onset of the summer monsoon.

Although the climatological states of the atmosphere and ocean in South Asia are very different in March and May, the spatial distributions of the changes in atmospheric circulation and precipitation resulting from the thermal forcing of the Tibetan Plateau are similar (Fig. 5). The subtle differences between the response structures in these two months are mainly manifested in two ways. First, the magnitude of precipitation and the wind speed response in March (Fig. 5a) are smaller than those in May (Fig. 5b), especially in eastern China, South Asia, and the South China Sea. Second, the significant response in the westward reaches in March (Fig. 5a) is limited to the east of the Arabian Peninsula, whereas in May it extends to the Mediterranean region and northeastern Africa (Fig. 5b). In South Asia, the response (e.g., the cyclonic circulation around the Tibetan Plateau, the westerly winds over the northern Indian Ocean, and the general pattern of precipitation changes) shows strong consistency in March and May (Figs. 5a,b). The precipitation is reduced west of $90^{\circ} \mathrm{E}$ and is increased east of $90^{\circ} \mathrm{E}$. However, the precipitation at approximately $90^{\circ} \mathrm{E}$ shows subtle differences, with reductions in precipitation in the Bay of Bengal and the southeast Indian Ocean in March and increases in these regions in May (Figs. 5a,b). This may result from the vertical circulation changes that will be discussed in section $3 \mathrm{e}$. 

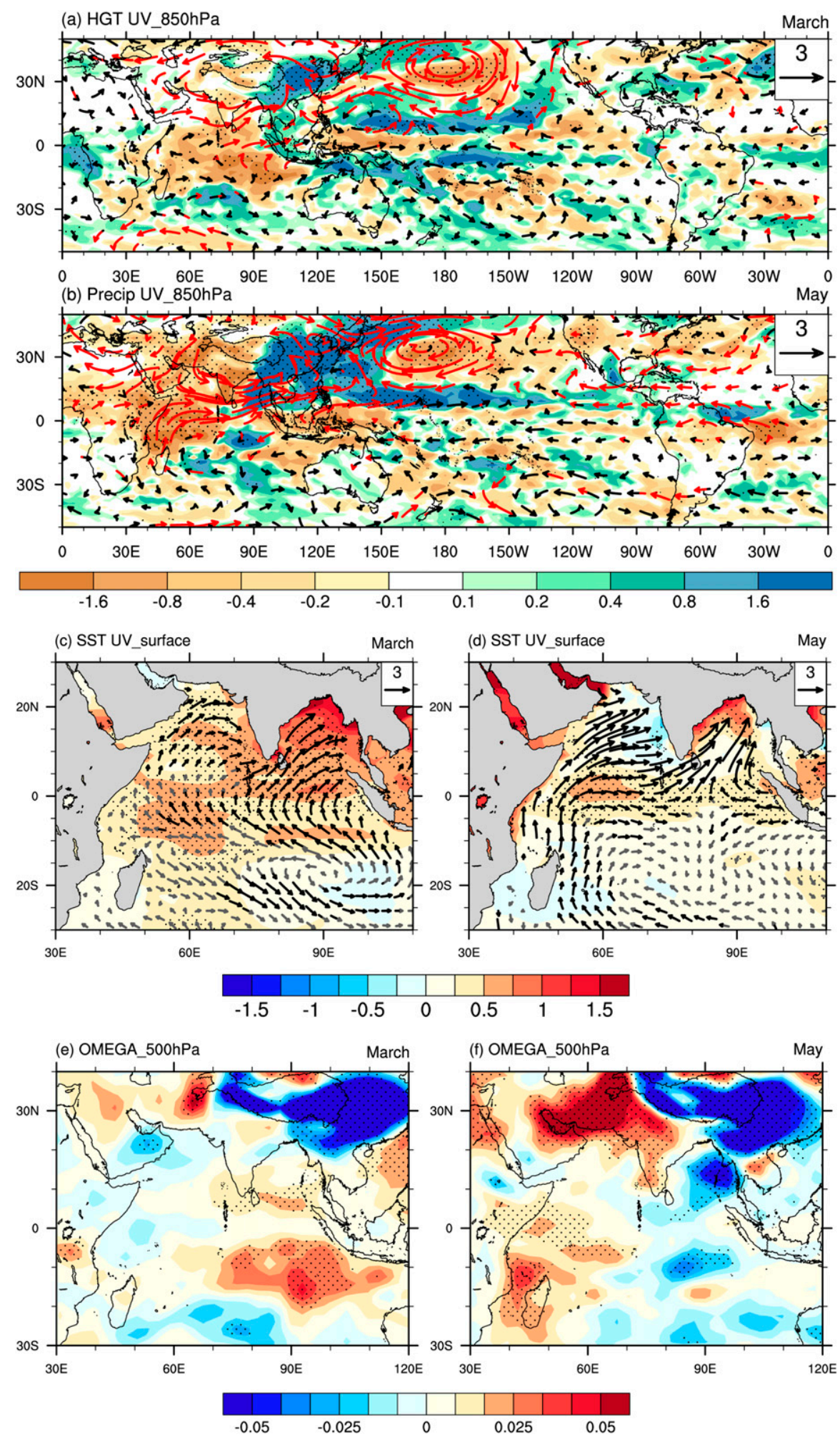

FIG. 5. Precipitation (shading; $\mathrm{mm}$ ) and circulation (vectors; $\mathrm{m} \mathrm{s}^{-1}$ ) changes due to TP thermal forcing at $850 \mathrm{hPa}$ in (a) March and (b) May according to CTRL and NoTPSH experiments. Dotted areas and red vectors indicate statistical significance at the $95 \%$ confidence level according to the two-sided $t$ test. (c),(d) As in Fig. 3a, but for March and May, respectively. (e),(f) Vertical velocity (shading; $\mathrm{Pa} \mathrm{s}^{-1}$ ) changes due to Tibetan Plateau thermal forcing at $500 \mathrm{hPa}$ in March and May, respectively, according to CTRL and NoTPSH experiments. Dotted areas indicate statistical significance at the $95 \%$ confidence level according to the two-sided $t$ test. 
In addition, as the Somali jet effectively increased in May (Fig. 5b), more air was transported to the north from the lower level, and a compensatory descend was present on the east coast of Africa and near Madagascar (Fig. 5f).

The southwest surface wind response is more significant over the eastern Indian Ocean than that over the western Indian Ocean in March (Fig. 5c), and the warm center is located in the northern Bay of Bengal. The tropical Indian Ocean presents a significant warming response before monsoon onset. By contrast, the southwesterly response becomes stronger in May and extends to the western Indian Ocean, but the overall warming of the SST is weaker than that in March. Only the equatorial Indian Ocean and the northern Bay of Bengal show a significant but weak warming response (Fig. 5d). A synthesis of the similar response pattern against the contrary background circulation through March and May in South Asia shows that the evaporation process and SST over the Indian Ocean are likely to evolve in opposite ways (Fig. 3e). As the temperature of the mixed layer is a good proxy for the SST, an analysis of the temperature tendency of the mixed layer provides more detailed information about the mechanism of this process.

\section{c. Mixed-layer temperature analysis}

We adopted the heat budget equation of Qiu (2000) and He et al. (2018) to determine the cause of the changes in temperature in the Indian Ocean:

$$
\underbrace{\frac{\partial T_{m}}{\partial t}}_{d T}=\underbrace{\frac{Q_{\mathrm{net}}-Q_{d}}{\rho_{0} C_{p} H}}_{Q_{m}}-\underbrace{\mathbf{U} \cdot \nabla T_{m}}_{\text {Adv }}-\underbrace{\frac{w_{\mathrm{ent}}\left(T_{m}-T_{d}\right)}{H}}_{\text {Ent }}+\underbrace{\text { Res }}_{\text {Res }}
$$

where $T_{m}$ is the monthly averaged mixed-layer temperature, $C_{p}=3996 \mathrm{~J} \mathrm{~kg}^{-1} \mathrm{~K}^{-1}$ is the specific heat of seawater, $\rho_{0}=$ $1029 \mathrm{~kg} \mathrm{~m}^{-3}$ is the density of seawater, and $T_{d}$ is the water temperature at the base of the mixed layer. Also, $H$ is the mixed layer depth, defined as the depth of the isotherm $0.2^{\circ} \mathrm{C}$ lower than the temperature at $-10 \mathrm{~m}$ in LICOM2 (Liu et al. 2012); $Q_{\text {net }}$ represents the net surface heat flux, the sum of the surface sensible heat flux $Q_{\mathrm{sh}}$, the latent heat flux $Q_{\mathrm{lh}}$, the shortwave radiation flux $Q_{\mathrm{sw}}$, and the longwave radiation flux $Q_{\text {lw }}$ :

$$
Q_{\text {net }}=Q_{\mathrm{sw}}+Q_{\mathrm{lw}}+Q_{\mathrm{sh}}+Q_{\mathrm{lh}} .
$$

The term $Q_{d}$ is the shortwave flux that penetrates through the mixed layer, calculated following Paulson and Simpson (1977):

$$
Q_{d}=Q_{\mathrm{sw}}\left[R e^{-H / \zeta_{1}}+(1-R) e^{-H / \zeta_{2}}\right]
$$

where $Q_{\text {sw }}$ represents the downward shortwave radiation flux at the sea surface and $R=0.58, \zeta_{1}=0.35 \mathrm{~m}$, and $\zeta_{2}=23 \mathrm{~m}$ are empirical parameters chosen following Rosati and Miyakoda (1988).

In Eq. (2), the first term on the left-hand side is the temperature tendency term, representing the local temperature change rate (denoted as the $d T$ term). The first term on the right-hand side is the heat flux forcing term, which represents the effects of the exchange of heat flux over the sea surface (denoted as the $Q_{m}$ term). The second term on the right-hand side is horizontal advection (denoted as the Adv term), and the third term is vertical entrainment (denoted as the Ent term). These equations are calculated based on the monthly output data of the ocean and atmosphere modules in the model. Because the intramonth scale process is ignored, the residual term (denoted as the Res term) is relatively large but does not affect the results' validity (Du et al. 2005).

The changes in each term in Eq. (2) show that the temperature tendency of the mixed layer in the Indian Ocean in March is the opposite of the tendency in May (Figs. 6a,f). In March, the $d T$ term is positive in the central and eastern Indian Ocean, especially in the Bay of Bengal (Fig. 6a), and the main contribution is the $Q_{m}$ term (Fig. 6k). The change in this term indicates that more of the heat flux is accepted by the ocean at the air-sea interface (Fig. 6b). The Adv term makes a negative contribution in the northern Indian Ocean (Fig. 6c), which is related to the southward flow of the northern offshore upwelling and the temperature gradient of the climatological state. Because the southwesterly response weakens the background northeasterly, the mixed layer becomes shallower as the wind speed decreases so that the mixing and entrainment of warm surface water and cold subsurface water is reduced, resulting in a positive contribution to mixed-layer warming in the Bay of Bengal (Fig. 6d). The Res term can also be interpreted as the general effects of subgrid-scale and intramonthly processes, offsetting the warming contribution from $Q_{m}$ (Fig. 6e). A higher-resolution CGCM with daily outputs may be required to provide a better explanation of the residual term.

Further analysis of each component of the $Q_{m}$ term showed that the dominant contribution to the increase in the net heat flux at the sea surface is the strengthening of $Q_{\text {sw }}$ (Fig. 7a) and the weakening of evaporation cooling (Fig. 7d), which is consistent with the results of Duan et al. (2008). The increase in $Q_{\text {sw }}$ over the eastern Indian Ocean is related to a decrease in cloud cover, which is also reflected in reduced precipitation in the Bay of Bengal and the southeast Indian Ocean (Fig. 5a). The surface wind speed decreases, and the evaporation process is suppressed. Therefore, more heat is retained in the northern Indian Ocean (Fig. 7d). Another related change is the penetration of shortwave radiation to the bottom of the mixed layer. As the surface wind speed weakens, the shallower mixed layer depth allows more shortwave radiation to penetrate through the mixed layer rather than being absorbed in this layer (Fig. 7e).

Although most regions of the Indian Ocean retain an overall positive SST response in May (Fig. 5d), the magnitude is much weaker than that in March (Fig. 5c). This is consistent with the negative temperature tendency in May (Fig. 3e). Figure $6 f$ shows the spatial distribution of the influence of thermal forcing by the Tibetan Plateau on the Indian Ocean SST tendency. The equatorial and northern Indian Ocean show a significant cooling tendency in May, especially in the Bay of Bengal (Fig. 6f). The $Q_{m}$ term contributes the most to the cooling effect (Figs. 6g,k). The Adv term shows similar cooling effects in the Arabian Sea as in March (Fig. 6h). The Ent term also contributes to the cooling effect in the eastern Arabian Sea, the western Bay of Bengal, and the southwestern Indian Ocean (Fig. 6i). 

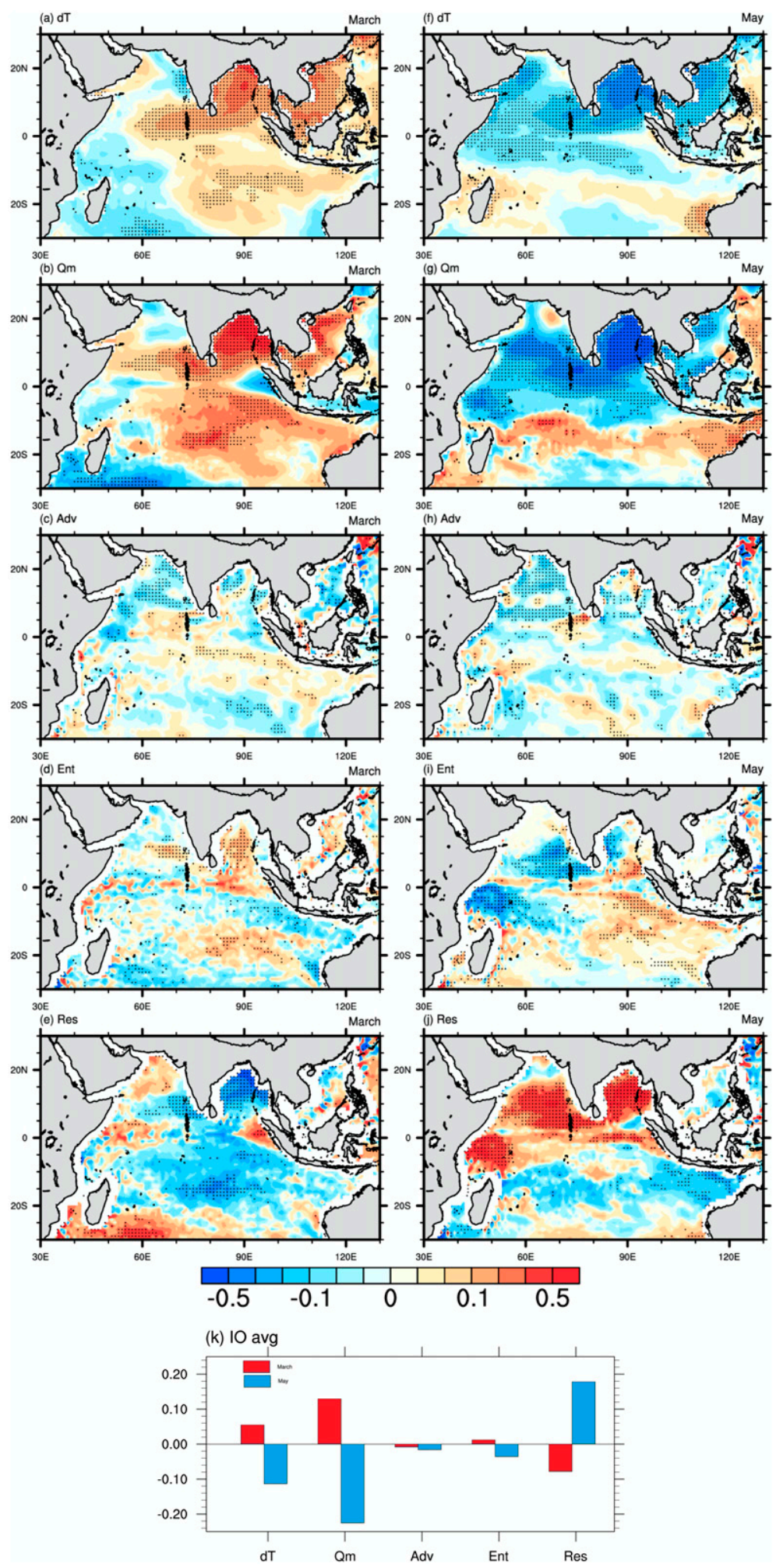

FIG. 6. Differences in the (a) $d T$, (b) $Q_{m}$, (c) Adv, (d) Ent, and (e) Res terms in the thermal equation between the CTRL and NoTPSH experiments in March $\left(10^{-6} \mathrm{~K} \mathrm{~s}^{-1}\right)$. Dotted areas indicate statistical significance at the $95 \%$ confidence level according to the two-sided $t$ test. (f)-(j) As in (a)-(e), but for May. (k) Areaaveraged results over the tropical Indian Ocean $\left(10^{\circ} \mathrm{S}-20^{\circ} \mathrm{N}, 30^{\circ}-100^{\circ} \mathrm{E}\right)$ for $(\mathrm{a})-(\mathrm{j})$. 

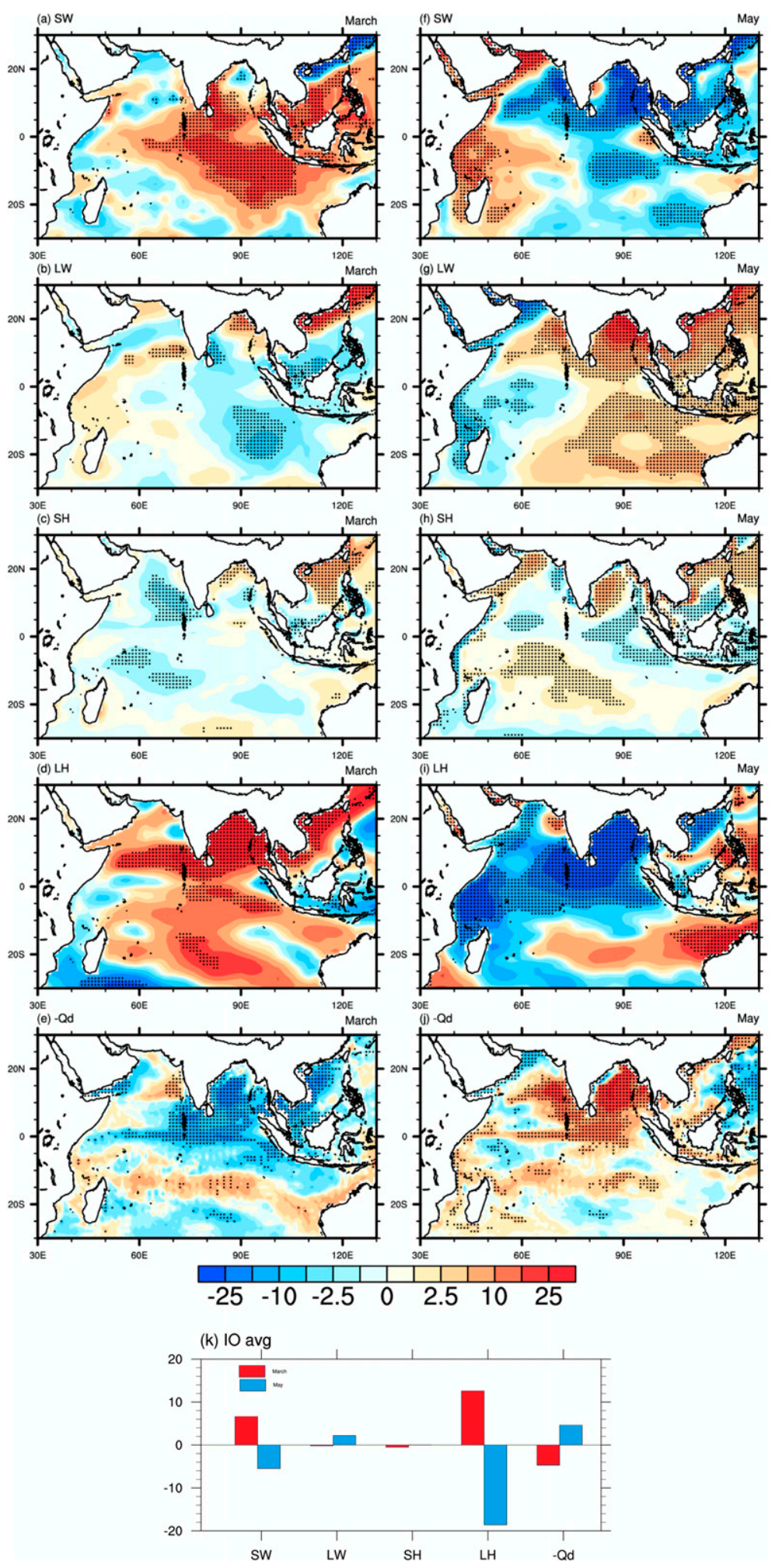

FIG. 7. (a) Net shortwave radiation flux, (b) net longwave radiation flux, (c) sensible heat flux, (d) latent heat flux, and (e) penetrating shortwave radiation flux at the bottom of the mixed layer changes due to Tibetan Plateau thermal forcing in March according to CTRL and NoTPSH experiments $\left(\mathrm{W} \mathrm{m}^{-2}\right)$. Downward is positive. Dotted areas indicate statistical significance at the $95 \%$ confidence level according to the two-sided $t$ test. (f)-(j) As in (a)-(e), but for May. (k) Area-averaged results over the tropical Indian Ocean $\left(10^{\circ} \mathrm{S}-20^{\circ} \mathrm{N}, 30^{\circ}-100^{\circ} \mathrm{E}\right)$ for (a)-(j). 


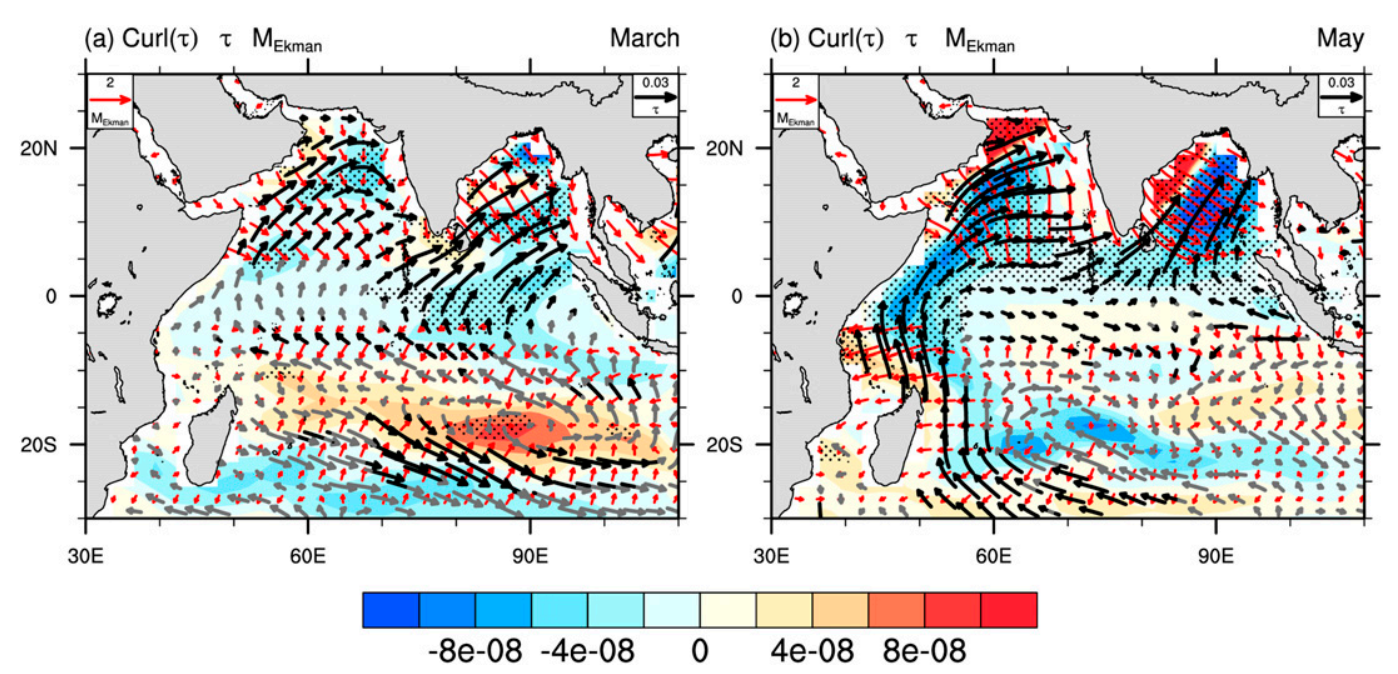

FIG. 8. Sea surface wind stress (black and gray vector; $\mathrm{N} \mathrm{m}^{-2}$ ), its curl (shading; $\mathrm{N} \mathrm{m}^{-3}$ ), and Ekman transport estimated by the surface wind stress (red vector; $\mathrm{t} \mathrm{m}^{-1} \mathrm{~s}^{-1}$ ) changes due to Tibetan Plateau thermal forcing in (a) March and (b) May according to CTRL and NoTPSH experiments. Dotted areas and black vectors indicate statistical significance at the $95 \%$ confidence level according to the two-sided $t$ test.

The $Q_{\text {sw }}$ and $Q_{\text {lh }}$ anomalies still dominate the changes in the $Q_{m}$ term in May (Figs. 7f-j), although $Q_{\text {lw }}$ becomes more important (Figs. 7b,g). Notably, $Q_{\text {sw }}$ decreases in the eastern Indian Ocean and increases in the west along the African coast (Fig. 7f) due to the changes in cloud cover. More cloud cover over the eastern Indian Ocean reduces the amount of solar radiation reaching the sea surface and prevents the longwave radiation emitted from the sea surface from being lost to space. This explains why the changes in $Q_{\text {lw }}$ and $Q_{\text {sw }}$ show a similar pattern but with the opposite signal (Figs. $7 \mathrm{f}, \mathrm{g}$ ). But the overall warming effect of $Q_{\text {sw }}$ response is larger than the cooling effect of $Q_{\mathrm{lw}}$ response (Fig. 7k). Overall $Q_{\mathrm{lh}}$ weakens in the northern and equatorial Indian Ocean (Fig. 7i), mainly due to the increased southwesterlies, which increase evaporation. The increased surface wind stirs the seawater more vigorously, increasing the depth of the mixed layer and reducing the penetration of shortwave radiation, which compensates for the heat lost from the surface (Fig. 7j). Finally, $Q_{\text {sh }}$ has some regional effects, but these are negligible (Fig. 7k).

In sum, the changes in the mixed layer temperature tendency caused by the thermal forcing of the Tibetan Plateau are positive in March and negative in May, mainly as a result of the reversal of the $Q_{m}$ term.

\section{d. Wind-driven currents and related Walker circulation}

In addition to the thermal changes in the mixed layer, the experiments show that the wind-driven circulation also exhibits significant changes due to the thermal forcing of the Tibetan Plateau. However, unlike the total reversal of the response of the temperature tendency in March and May, the related changes in circulation show a similar structure in boreal spring. Anomalous southeastward Ekman transport can be observed in the surface layer (red vectors in Fig. 8), as the surface wind stress shows an increased southwesterly flow across the northern Indian Ocean in March and May.
There are, however, apparent differences in the intensity and range of these changes. The overall wind stress response in the northern Indian Ocean in May is stronger than that in March. The main response area in March covers almost the entire tropical Indian Ocean, with a wind stress response between $20^{\circ} \mathrm{N}$ and $20^{\circ} \mathrm{S}$. In the southeast Indian Ocean, in particular, the significant response is mainly manifested as a convergence zone with a demarcation line near $20^{\circ} \mathrm{S}$. The Ekman transport is southward on the north side and northward on the south side (red vectors in Fig. 8a). In May, the significant response area mainly occurs in the Northern Hemisphere and along a narrow belt on the eastern coast of Africa. This is related to the appearance of the Somali jet and the seasonal evolution of the climatological local Hadley circulation.

The Ekman transport response is generally southeastward in March but strengthens in May and becomes southward in the Arabian Sea and eastward in the Bay of Bengal. There is a negative vorticity response in most of the northern Indian Ocean (shading in Fig. 8b). According to the Ekman pumping theory, this represents significant convergent subsidence at the bottom of the Ekman layer in the northern Indian Ocean. A positive vorticity response is seen in the northwest corner of the Arabian Sea and the Bay of Bengal as a result of wind speed shear caused by the friction of the underlying land surface (Fig. 8b).

In March, the surface $(0-60 \mathrm{~m})$ currents near the equator are significantly affected. The westerly drift along the equator is strengthened (Fig. 9a), and anomalous southward currents appear on the eastern side of the Arabian Sea. These two anomalous currents merge on the south side of the Indian Peninsula and flow across the equator to the Southern Hemisphere on the south side of the Bay of Bengal (Fig. 9a). The subsurface $(60-400 \mathrm{~m})$ layer is hardly affected at this time, with the only significant change in the southward current along the eastern side of the Arabian Sea (Fig. 9c). 

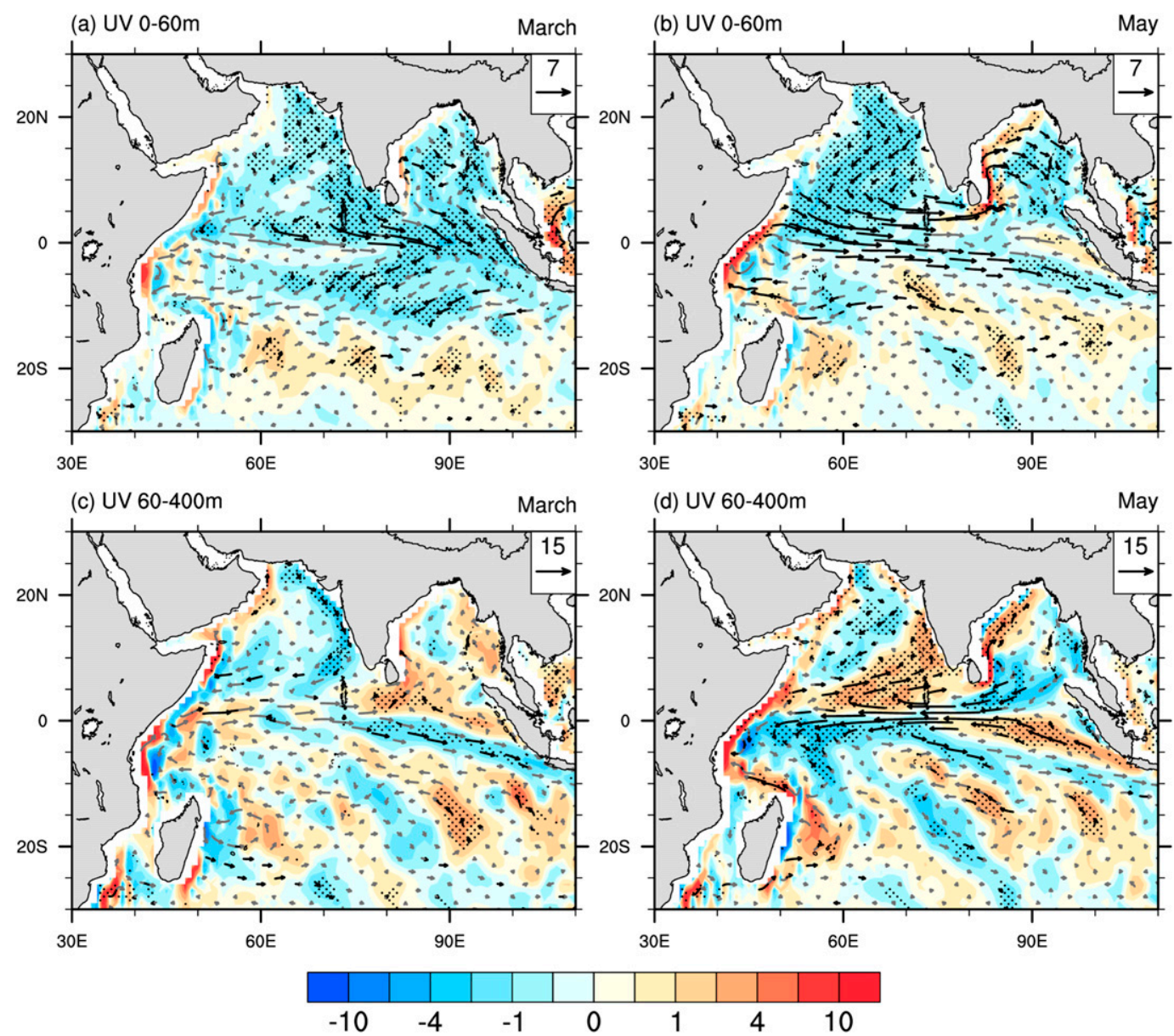

FIG. 9. Sea current speed (vectors; $\mathrm{cm} \mathrm{s}^{-1}$ ) averaged from the surface to $60 \mathrm{~m}$ and its meridional component (shading; $\mathrm{cm} \mathrm{s}^{-1}$ ) changes due to Tibetan Plateau thermal forcing in (a) March and (b) May, according to CTRL and NoTPSH experiments. (c),(d) As in (a) and (b), but averaged from 60 to $400 \mathrm{~m}$.

After the monsoon's onset, both the surface and subsurface currents near the equator are affected and correspond well with the Walker circulation. The response of the wind-driven circulation in May is very different from that in March. In the Arabian Sea, the currents from northeast to southwest are strengthened and turn eastward near the Somali Sea at approximately $5^{\circ} \mathrm{N}$ and then divide into two branches. One branch passes through Sri Lanka and flows north along the western side of the Bay of Bengal, corresponding to the strengthening of the southwestern monsoon drift current. The other branch merges with the strengthened northbound East African Coastal Current and the Somali Current and flows across the equator in the western Indian Ocean to the Southern Hemisphere before continuing eastward to the southern side of Sumatra (Fig. 9b). The Westward Equatorial Undercurrent is significantly strengthened in the subsurface layer. In the eastern part of the Indian Ocean, the equatorial westward undercurrent attracts two branches, one from the Bay of Bengal and the other from the southern side of Sumatra. After passing through the southern tip of the Indian Peninsula, it divides into two branches. The northern branch replenishes the seawater lost from the surface layer of the Arabian
Sea, and the southern branch continues westward, gradually spreading southward along the way (Fig. 9d).

This analysis in the horizontal direction shows that the significant changes in the currents mainly include those parts of the northern Indian Ocean that are closer to the Tibetan Plateau. However, the oceanic vertical overturning circulation along the equator is also affected, especially in May (Figs. 9 and 10). The changes in the equatorial ocean current are closely related to the local Walker circulation. In March, the anomalous atmospheric circulation over the equator is dominated by sinking, with westerly winds in the upper level at $200 \mathrm{hPa}$, weak easterly winds at $400-700 \mathrm{hPa}$, and westerly winds at lower levels in the eastern Indian Ocean (Fig. 10a). This explains why the eastward drift response is more significant in the eastern Indian Ocean (Fig. 10c). The eastward currents result in downwelling near Sumatra, which leads to local changes in temperature: warm surface water piles up in the east and warms the subsurface layer as it sinks near the shore (Fig. 10c).

An easterly wind anomaly appears in the upper layer near $200 \mathrm{hPa}$ in May. A significant sinking branch anomaly was found to the west of $70^{\circ} \mathrm{E}$ at $250-400 \mathrm{hPa}$, and a weak ascending 

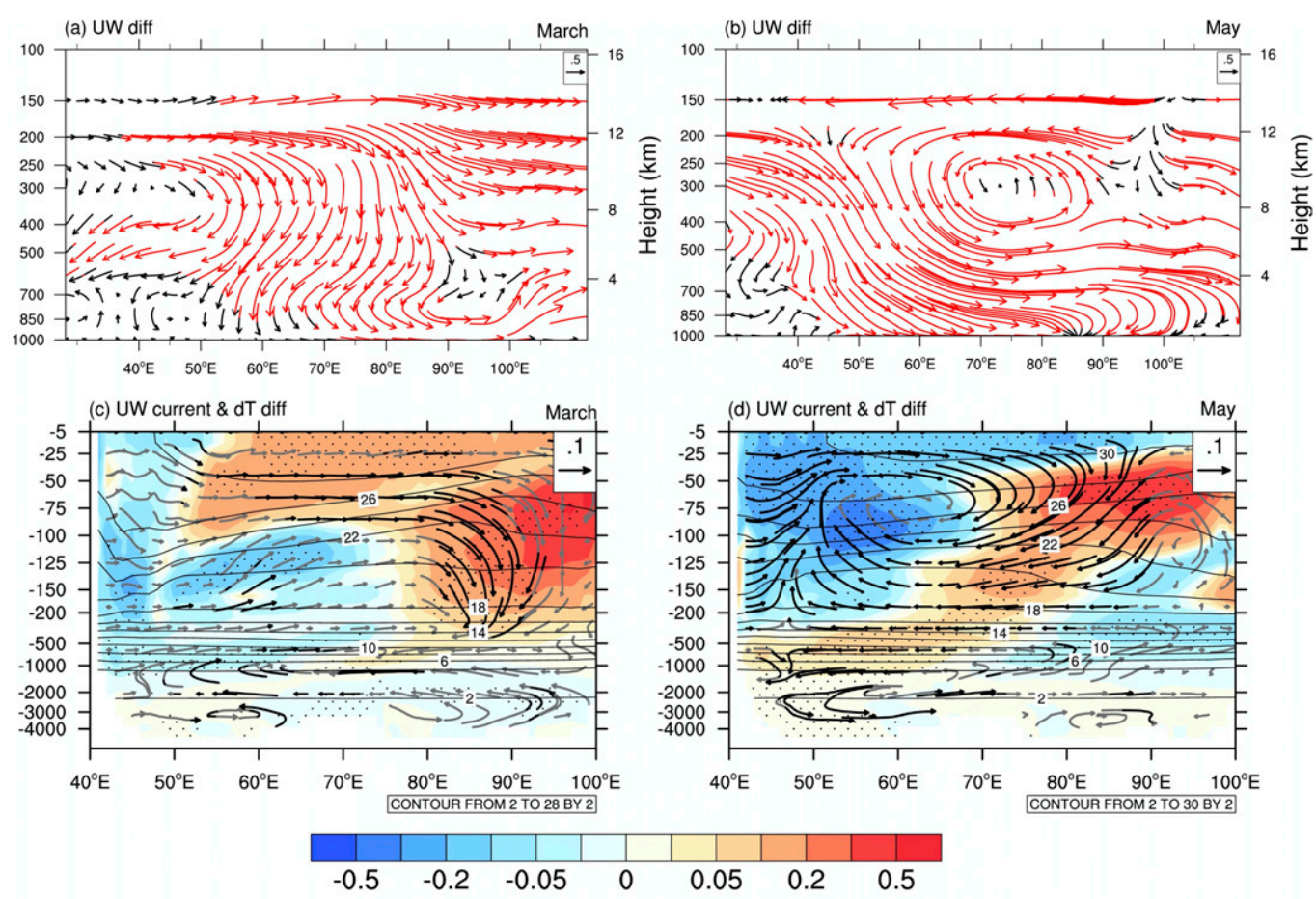

FIG. 10. Meridionally averaged $\left(5^{\circ} \mathrm{S}-5^{\circ} \mathrm{N}\right)$ atmospheric circulation (vectors; $\mathrm{m} \mathrm{s}^{-1}$ for horizontal, $\mathrm{Pa} \mathrm{s}^{-1}$ for vertical; the vertical velocity has been magnified by 100 for visualization convenience) changes due to Tibetan Plateau thermal forcing in (a) March and (b) May according to CTRL and NoTPSH experiments. Red vectors indicate statistical significance at the $95 \%$ confidence level according to the two-sided $t$ test. Also shown are meridionally averaged $\left(3^{\circ} \mathrm{S}-3^{\circ} \mathrm{N}\right)$ sea current speed (vectors; $\left.\mathrm{m}^{2} \mathrm{~s}^{-1}\right)$, temperature tendency (shading; $\mathrm{K}$ month ${ }^{-1}$ ), and climatological temperature (contours; ${ }^{\circ} \mathrm{C}$ ) changes due to Tibetan Plateau thermal forcing according to CTRL and NoTPSH experiments in (c) March and (d) May. Dotted areas and black vectors indicate statistical significance at the $95 \%$ confidence level according to the two-sided $t$ test.

branch appeared to the east. Below $500 \mathrm{hPa}$, a uniform westerly anomaly dominated the lower levels, forming a strengthened Walker circulation (Fig. 10b). This is similar to the Indo-Pacific gear coupling system proposed by Rao and Goswami (1988) and Meng and Wu (2000). Krishnamurthy and Goswami (2000) also found similar anomalies in the circulation structure.

Our experiment further illustrates that the thermal forcing of the Tibetan Plateau is sufficient to influence this circulation structure after the onset of the monsoon. The significant difference compared with March may also result from the evolution of the background circulation. The climatological local Walker circulation over the Indian Ocean becomes clearer in May and presents a closed feature (Figs. S4a,b). The vertical structure of the response of the ocean currents shows good symmetry with this atmospheric response, reflecting the anomaly in the Walker circulation (Figs. 10b,d). In contrast with March, the offshore upwelling on the western side of the equatorial Indian Ocean becomes clearer, and the strengthened westerly wind drift becomes shallower. Although the eastern sinking branch can no longer reach 200-m depth, it is strengthened and widened. The central position of the sinking current moves westward from $85^{\circ} \mathrm{E}$ in March to approximately $75^{\circ} \mathrm{E}$. An equatorial undercurrent flowing from east to the west in the subsurface layer appears at a depth of 100-200 m, forming a complete zonal overturning circulation response. In addition, the sea temperature at $0-50 \mathrm{~m}$ in the surface layer decreases as a result of the increase in evaporation from the sea surface (Fig. 7i), although the cooling caused by offshore upwelling near the African coast cannot be ignored (Fig. 6i).

\section{e. Local Hadley circulation and meridional wind-driven circulation}

The range of influence of the thermal forcing of the Tibetan Plateau in spring not only includes the northern and equatorial Indian Oceans but also reaches the Southern Hemisphere (Figs. 5-8). This suggests that the cross-equatorial circulation, including the local Hadley circulation and the meridional circulation in the ocean, may also be modulated by the thermal forcing of the Tibetan Plateau.

The latitude-altitude cross section of the zonally averaged winds shows that the influence of the thermal forcing of the Tibetan Plateau on the local Hadley circulation in March and May is different in range, shape, and position (Figs. 11a,b). In March, a strong ascending branch driven by the surface sensible heat over the Tibetan Plateau turns south at a height of $200-400 \mathrm{hPa}$ across the equator and then sinks near $10^{\circ} \mathrm{S}$ (Figs. 11a and 5e). This may explain the drying in the southeast 

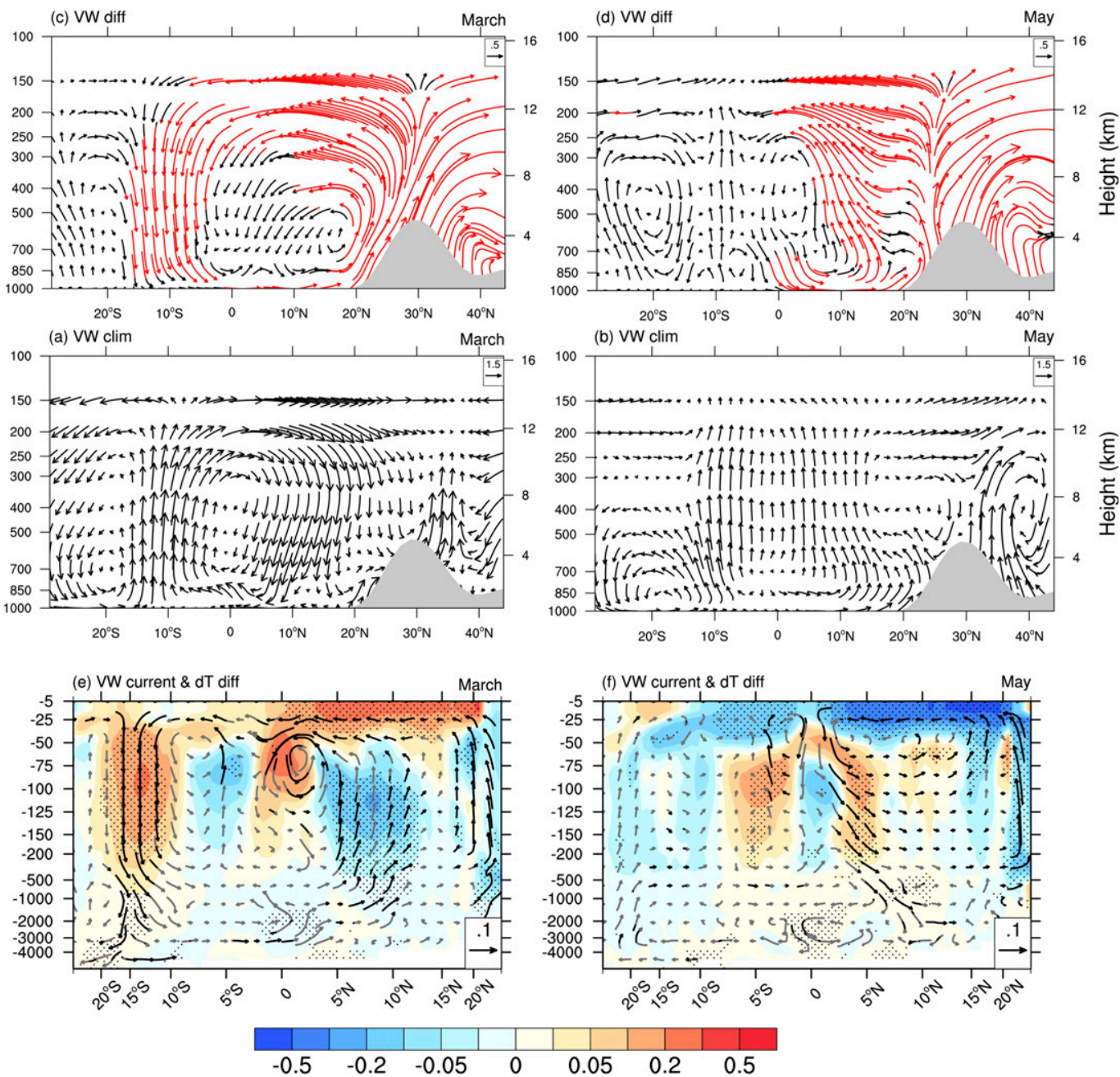

FIG. 11. (a) Atmospheric meridional circulation changes (vectors; $\mathrm{m} \mathrm{s}^{-1}$ for horizontal, $\mathrm{Pa} \mathrm{s}^{-1}$ for vertical; the vertical velocity has been magnified by 100 for visualization convenience) over the Indian Ocean (zonally averaged over $65^{\circ}-115^{\circ} \mathrm{E}$ ) due to Tibetan Plateau thermal forcing in March according to CTRL and NoTPSH experiments. Red vectors indicate statistical significance at the $95 \%$ confidence level according to the two-sided $t$ test. (b) As in (a), but for May. (c) Climate mean atmosphere meridional circulation in the CTRL over the Indian Ocean (zonally averaged over $65^{\circ}-115^{\circ} \mathrm{E}$ ) in March. (d) As in (c), but for May. (e) Ocean meridional circulation (vectors; $\mathrm{m} \mathrm{s}^{-1}$ for horizontal direction, $\mathrm{m} \mathrm{day}^{-1}$ for vertical direction) and temperature tendency (shading; $\mathrm{K} \mathrm{month}{ }^{-1}$ ) changes due to Tibetan Plateau thermal forcing in March according to CTRL and NoTPSH experiments (zonally averaged over $\left.40^{\circ}-100^{\circ} \mathrm{E}\right)$. (f) As in (e), but for May.

Indian Ocean (Figs. 5a,e). Then a weak northward backflow appears near $800 \mathrm{hPa}$ at lower levels (Fig. 11a). In May, the ascending branch near the Tibetan Plateau is accompanied by another branch in the south. Although the ascending movement is extended north of $10^{\circ} \mathrm{N}$ and turns south in the upper levels, the northerly wind in the upper levels does not cross the equator, resulting in weak descending motion near the equator. Therefore, the significant response range of the meridional circulation is restricted to the Northern Hemisphere (Fig. 11b).

A more intuitive perspective of the seasonal evolution of the climatological local Hadley circulation before and after the onset of the monsoon is as follows. The ascending branch of the local Hadley circulation over the Indian Ocean in March is located near $10^{\circ} \mathrm{S}$ (Fig. 11c). The high-level southerly flow on the north side of the equator crosses the equator and descends at $5^{\circ}-25^{\circ} \mathrm{N}$, reaching the top of the Tibetan Plateau (Fig. 11c). At this time, the northeast monsoon is projected to be northerly at the lower level of the local Hadley circulation. The structure of the changes in the meridional circulation induced by the thermal forcing of the Tibetan Plateau (Fig. 11a) is consistent with the background circulation in Fig. 11c in both shape and position but in the opposite direction. Therefore, the thermal forcing of the Tibetan Plateau obstructs the local Hadley circulation that crossed the equator before the onset of the monsoon. 
By May, the ascending branch of the climatological local Hadley circulation has progressed from $10^{\circ} \mathrm{S}$ to the equator and its width has spread in the meridional direction (Fig. 11d). Most importantly, it lost the cross-equator feature before (Figs. 11c,d). Meanwhile, after the South Asian monsoon's onset, the lowerlevel flow turns southwesterly, the opposite of the climatological local Hadley circulation. Below $700 \mathrm{hPa}$, areas from the north of $10^{\circ} \mathrm{N}$ to the southern slopes of the Tibetan Plateau are dominated by ascending motion, accompanied by a southerly flow (Fig. 11d). However, this southerly flow does not cancel the prior equatorward branch of the local Hadley circulation but changes into a northerly flow above $700 \mathrm{hPa}$. In other words, the Hadley circulation is lifted by the lower-level southeasterly monsoon while progressing northward in May, although the weak descending branch is still located above the Tibetan Plateau (Fig. 11d). The range of influence of the thermal forcing of the Tibetan Plateau, therefore, follows the evolution of the structure of the climatological local Hadley circulation.

Corresponding to the climatological local Hadley circulation evolution, the response range of the meridional wind-driven circulation in March is wider than that in May. The overall changes in the meridional circulation show a similar structure in March and May: upwelling in the north, a southward drift in the surface layer, and sinking in the south (Figs. 11e,f). A distinct feature in March is the downwelling with warming in the Southern Hemisphere (Fig. 11e). The center is located at $10^{\circ}-15^{\circ} \mathrm{S}$, just under the suppressed ascending branch of the climatological local Hadley circulation. A clear positive wind stress curl response can be observed at this location (Fig. 8a), which results from the anomalous descending movement shown in Fig. 11a. According to the Ekman pumping theory, the positive wind stress curl in the Southern Hemisphere results in downwelling due to the convergence of water. Southward Ekman transport is strong in the surface layer in the warmer temperatures of the northern Indian Ocean, and it continues southward in the Southern Hemisphere after a short break near the equator.

The subsurface layer in the northern Indian Ocean shows general upwelling, compensating for the loss caused by southward transport in the surface layer. In May, the meridional circulation response remains in the same direction but is confined to the Northern Hemisphere. Southward Ekman transport in the surface layer still attracts offshore upwellings in the north, but the drift stops near the equator and begins to sink. The currents sink on the north side of the equator (Fig. 11f) and flow back to the north in the subsurface layer, constructing a clear closed meridional overturning circulation. Overall, the response of the local Hadley circulation and the meridional wind-driven circulation in the Indian Ocean have a similar structure, but the response range converges to the north of the equator after the monsoon onset.

\section{Discussion and conclusions}

By conducting two groups of experiments based on a CGCM simulation, we analyzed the modulation effect of the thermal forcing of the Tibetan Plateau on the atmospheric circulation, sea temperature, and wind-driven circulation in the Indian Ocean region before and after the onset of the Asian summer monsoon from a climatological perspective. Our main findings can be summarized as follows.

1) The thermal forcing of the Tibetan Plateau in spring can significantly affect the SST in various ocean basins in the Northern Hemisphere, including warming of the northwest Pacific Ocean, the dipole response of the North Atlantic Ocean, and the overall warming of the tropical Indian Ocean. The change in the SST of the Indian Ocean is smaller than that at mid- to high latitudes, but the relative change is larger. A significant warming SST response can be observed in the tropical Indian Ocean, which persists through the following months and brings an all-year-round warming effect to the climatological state.

2) Although the overall response of the Indian Ocean SST in boreal spring shows basinwide warming, there are also differences how the thermal forcing of the Tibetan Plateau modulates the atmosphere and ocean in this region before and after the onset of the monsoon. Climatologically, before the onset of the monsoon, the wind direction at lower levels in South Asia is northeasterly in March, but it changes to southwesterly in May. However, the modulating effects of the thermal forcing of the Tibetan Plateau on the atmosphere retain a consistent southwesterly wind response over the northern Indian Ocean. This disagreement between the reversal in the background circulation and the consistent response pattern results in opposite changes in wind evaporation, in which the Indian Ocean SST tendency is positive in March but negative in May. In March, before the monsoon's onset, the background northeasterly flow is suppressed by the southwesterly flow induced by the thermal forcing of the Tibetan Plateau. The wind speed therefore decreases, and evaporation weakens, allowing the ocean to retain more heat and the SST to increase. However, in May, after the onset of the monsoon, the background southwesterly flow is accelerated by the southwesterly flow induced by the thermal forcing of the Tibetan Plateau. Therefore, the wind speed increases, and evaporation strengthens, allowing the ocean to lose more heat and the SST to decrease.

3) The wind-driven circulation in the ocean is also modulated by the thermal forcing of the Tibetan Plateau. In the northern Indian Ocean, the southeastward Ekman transport response caused by anomalous southwesterly winds is seen throughout boreal spring, and the response is stronger and deeper after the onset of the monsoon. As the local Walker circulation is modulated by the thermal forcing of the Tibetan Plateau, the zonal circulation in the ocean also changes correspondingly. Before the onset of the monsoon, the westerly drift of the equatorial surface water is strengthened and forms downwellings in the east; after the onset of the monsoon, the westerly drift is strengthened further, together with upwelling in the west and a westward backflow in the subsurface, forming a closed zonal circulation anomaly.

4) Figure 12 summarizes the meridional changes in the atmospheric and oceanic circulations as a result of the thermal forcing of the Tibetan Plateau. Before the onset of the monsoon, the response of the atmospheric circulation weakens the local Hadley circulation that crosses the 

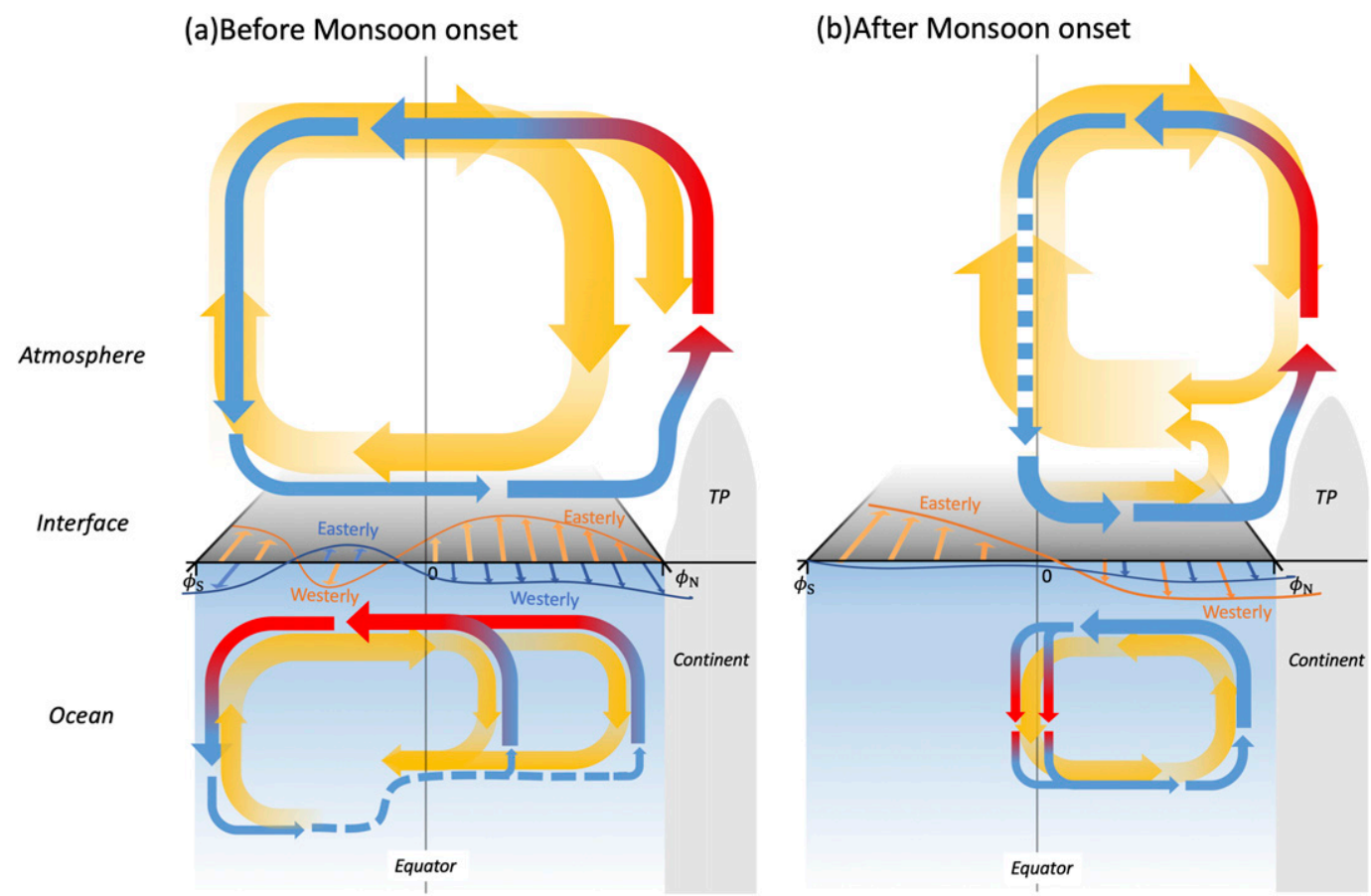

FIG. 12. Schematic of atmosphere and ocean circulations across the Indian Ocean in the CGCM. Yellow vectors denote the climatological state. Before the monsoon onset, the local Hadley circulation has strong cross-equatorial characteristics, rising to the south of the equator with southerlies in the upper level, sinking over the Indian subcontinent and the TP, and returning as northerlies in the lower level. In the ocean, driven by the easterly surface wind and Coriolis force, the water transport in the surface layer is northward with convergence subsidence in the middle of the northern Indian Ocean due to sea surface wind shear (details are shown in Fig. S5) and onshore downwellings at the northern boundary. The blue/red vectors denote wind and sea current changes due to the Tibetan Plateau thermal forcing. The Tibetan Plateau is located below the descending branch of the local Hadley circulation. Therefore, heating can reversely push the local Hadley circulation and weaken it. The surface ocean currents are also weakened due to the westerly surface wind anomaly. After the monsoon onset, the local Hadley circulation constricts with its rising branch marching to the north. Meanwhile, it is "lifted up" by the southerly monsoon from the bottom. While Tibetan Plateau thermal forcing still pushes the Hadley circulation at the upper level, it can also strengthen the southwest monsoon at the lower level. At this time, the enhanced southwesterly surface wind results in southward transport that sinks near the equator, generally accelerating the meridional circulation in the northern Indian Ocean [after Schneider et al. (2014)].

equator, resulting in a cross-equatorial anomaly in the wind-driven circulation (Fig. 12a). After the onset of the monsoon and the structural evolution of the climatological local Hadley circulation in the Indian Ocean, the thermal forcing of the Tibetan Plateau obstructs the local Hadley circulation in the upper levels of the atmosphere in the Northern Hemisphere while accelerating the southwesterly surface winds at lower levels (Fig. 12b). The meridional overturning circulation in the northern Indian Ocean is also accelerated.

Therefore, there is a time window in which the thermal forcing of the Tibetan Plateau influences the Southern Hemisphere and the interhemispheric mass/heat exchange before the onset of the monsoon. In a subsequent paper, we plan to analyze the changes in interhemispheric mass/heat transport due to the thermal forcing of the Tibetan Plateau. A quantitative result will be presented based on CGCM experiments to provide a deeper understanding of the role of the Tibetan Plateau heat source under the current background of global warming and asymmetrical interhemispheric warming.

Experiments with or without a Tibetan Plateau heat source may provide insights into the role of the thermal forcing of the Tibetan Plateau in Earth's climate system, but whether these phenomena and mechanisms will help observation-based applications deserves further evaluation. Based on the opposite response in the Indian Ocean before and after the onset of the monsoon, we should be more careful in defining and choosing the seasons when discussing the relationship between the tropical monsoon and the subtropical climate so that we do not ignore the seasonal reversal and observe only an average response.

The significant changes in the local Walker circulation and related zonal overturning circulation in the equatorial Indian Ocean show that not only can ENSO influence the Indian Ocean variability through the "atmosphere bridge" but also the Tibetan Plateau thermal forcing. However, whether the 
Indian Ocean basin mode and Indian Ocean dipole mode are significantly affected by the Tibetan Plateau still deserves further analysis. In addition to the wind-driven circulation, changes in the thermohaline circulation in the northern Indian Ocean are also of concern and will be included in future research. The modulation of the thermal forcing of the Tibetan Plateau in May can extend to the distant Somali jet and even farther to the south. Although this is related to the support of the background circulation, it may not be simply explained by a single heat pump effect. Perhaps the appearance of monsoon precipitation in South Asia also plays a part as a bridge. Besides, the relationship between precipitation and overturning vertical motions is not fully addressed in this study, and the specific mechanism needs to be verified by an additional approach.

Acknowledgments. This study was funded by the National Natural Science Foundation of China National Outstanding Youth Foundation of China (41725018), Young Scientists Fund (42005034), and Key Programme (42030602). The paper benefited from support for the model technique from Bian He and Ruizao Sun, who helped with the experiments.

\section{REFERENCES}

Abe, M., M. Hori, T. Yasunari, and A. Kitoh, 2013: Effects of the Tibetan Plateau on the onset of the summer monsoon in South Asia: The role of the air-sea interaction. J. Geophys. Res., 118, 1760-1776, https://doi.org/10.1002/jgrd.50210.

Baldwin, J. W., G. A. Vecchi, and S. Bordoni, 2019: The direct and ocean-mediated influence of Asian orography on tropical precipitation and cyclones. Climate Dyn., 53, 805-824, https:// doi.org/10.1007/s00382-019-04615-5.

Bao, Q., G. Wu, Y. Liu, J. Yang, Z. Wang, and T. Zhou, 2010: An introduction to the coupled model FGOALS1.1-s and its performance in East Asia. Adv. Atmos. Sci., 27, 1131-1142, https://doi.org/10.1007/s00376-010-9177-1.

— , and Coauthors, 2013: The Flexible Global Ocean-AtmosphereLand System model, spectral version 2: FGOALS-s2. Adv. Atmos. Sci., 30, 561-576, https://doi.org/10.1007/s00376-012-2113-9.

Boos, W. R., and Z. Kuang, 2010: Dominant control of the South Asian monsoon by orographic insulation versus plateau heating. Nature, 463, 218-222, https://doi.org/10.1038/nature08707.

$\longrightarrow$, and -2013 : Sensitivity of the South Asian monsoon to elevated and non-elevated heating. Sci. Rep., 3, 1192, https:// doi.org/10.1038/srep01192.

Briegleb, P., M. Bitz, C. Hunke, H. Lipscomb, M. Holland, L. Schramm, and E. Moritz, 2004: Scientific description of the sea ice component in the Community Climate System Model, version 3. NCAR Tech. Note NCAR/TN-463+STR, 70 pp., https://doi.org/10.5065/D6HH6H1P.

Broccoli, A. J., and S. Manabe, 1992: The effects of orography on midlatitude Northern Hemisphere dry climates. J. Climate, $\mathbf{5}$, 1181-1201, https://doi.org/10.1175/1520-0442(1992)005<1181: TEOOOM $>2.0 . \mathrm{CO} ; 2$.

Cadet, D. L., and B. C. Diehl, 1984: Interannual variability of surface fields over the Indian Ocean during recent decades. Mon. Wea. Rev., 112, 1921-1935, https://doi.org/10.1175/15200493(1984)112<1921:IVOSFO>2.0.CO;2.

Cayan, D. R., 1992: Latent and sensible heat flux anomalies over the northern oceans: Driving the sea surface temperature. J. Phys. Oceanogr., 22, 859-881, https://doi.org/10.1175/15200485(1992)022<0859:LASHFA > 2.0.CO;2.
Chen, X., and Q. You, 2017: Effect of Indian Ocean SST on Tibetan Plateau precipitation in the early rainy season. J. Climate, $\mathbf{3 0}$, 8973-8985, https://doi.org/10.1175/JCLI-D-16-0814.1.

Collins, W. D., and Coauthors, 2006: The Community Climate System Model version 3 (CCSM3). J. Climate, 19, 2122-2143, https://doi.org/10.1175/JCLI3761.1.

Du, Y., T. Qu, G. Meyers, Y. Masumoto, and H. Sasaki, 2005: Seasonal heat budget in the mixed layer of the southeastern tropical Indian Ocean in a high-resolution ocean general circulation model. J. Geophys. Res., 110, C04012, https://doi.org/ 10.1029/2004JC002845.

- S.-P. Xie, G. Huang, and K. Hu, 2009: Role of air-sea interaction in the long persistence of El Niño-induced north Indian Ocean warming. J. Climate, 22, 2023-2038, https:// doi.org/10.1175/2008JCLI2590.1.

Duan, A., and G. Wu, 2005: Role of the Tibetan Plateau thermal forcing in the summer climate patterns over subtropical Asia. Climate Dyn., 24, 793-807, https://doi.org/10.1007/s00382-004-0488-8.

- and - 2008: Weakening trend in the atmospheric heat source over the Tibetan Plateau during recent decades. Part I: Observations. J. Climate, 21, 3149-3164, https://doi.org/10.1175/ 2007JCLI1912.1.

_ C. Sui, and G. Wu, 2008: Simulation of local air-sea interaction in the great warm pool and its influence on Asian monsoon. J. Geophys. Res., 113, D22105, https://doi.org/ 10.1029/2008JD010520.

_, F. Li, M. Wang, and G. Wu, 2011: Persistent weakening trend in the spring sensible heat source over the Tibetan Plateau and its impact on the Asian summer monsoon. J. Climate, 24, 56715682, https://doi.org/10.1175/JCLI-D-11-00052.1.

Ebita, A., and Coauthors, 2011: The Japanese 55-year reanalysis "JRA-55": An interim report. SOLA, 7, 149-152, https:// doi.org/10.2151/sola.2011-038.

Fallah, B., U. Cubasch, K. Prömmel, and S. Sodoudi, 2015: A numerical model study on the behaviour of Asian summer monsoon and AMOC due to orographic forcing of Tibetan Plateau. Climate Dyn., 47, 1485-1495, https://doi.org/10.1007/ s00382-015-2914-5.

He, B., G. Wu, Y. Liu, and Q. Bao, 2015: Astronomical and hydrological perspective of mountain impacts on the Asian summer monsoon. Sci. Rep., 5, 17586, https://doi.org/10.1038/srep17586.

, Y. Liu, G. Wu, Z. Wang, and Q. Bao, 2018: The role of air-sea interactions in regulating the thermal effect of the TibetanIranian Plateau on the Asian summer monsoon. Climate Dyn., 52, 4227-4245, https://doi.org/10.1007/s00382-018-4377-y.

$\mathrm{Hu}$, J., and A. Duan, 2015: Relative contributions of the Tibetan Plateau thermal forcing and the Indian Ocean sea surface temperature basin mode to the interannual variability of the East Asian summer monsoon. Climate Dyn., 45, 2697-2711, https://doi.org/10.1007/s00382-015-2503-7.

Huang, R., 1985: The influence of the heat source anomaly over Tibetan Plateau on the Northern Hemispheric circulation anomalies. Acta Meteor. Sin., 43, 208-220, https://doi.org/ 10.11676/qxxb1985.026.

IPCC, 2013: Climate Change 2013: The Physical Science Basis. T. F. Stocker et al., Eds., Cambridge University Press, 1535 pp.

Ji, C., Y. Zhang, Q. Cheng, Y. Li, T. Jiang, and X. San Liang, 2018: On the relationship between the early spring Indian Ocean's sea surface temperature (SST) and the Tibetan Plateau atmospheric heat source in summer. Global Planet. Change, 164, 1-10, https://doi.org/10.1016/j.gloplacha.2018.02.011.

Kitoh, A., 2004: Effects of mountain uplift on East Asian summer climate investigated by a coupled atmosphere-ocean GCM. 
J. Climate, 17, 783-802, https://doi.org/10.1175/1520-0442(2004) 017<0783:EOMUOE $>2.0 . C O ; 2$.

Klein, S. A., B. J. Soden, and N.-C. Lau, 1999: Remote sea surface temperature variations during ENSO: Evidence for a tropical atmospheric bridge. J. Climate, 12, 917-932, https://doi.org/10.1175/1520-0442(1999)012<0917:RSSTVD> 2.0.CO;2.

Kobayashi, S., and Coauthors, 2015: The JRA-55 reanalysis: General specifications and basic characteristics. J. Meteor. Soc. Japan, 93, 5-48, https://doi.org/10.2151/jmsj.2015-001.

Krishnamurthy, V., and B. Goswami, 2000: Indian monsoonENSO relationship on interdecadal timescale. J. Climate, 13, 579-595, https://doi.org/10.1175/1520-0442(2000)013<0579: IMEROI $>2.0 . \mathrm{CO} ; 2$.

Leetmaa, A., 1972: The response of the Somali Current to the southwest monsoon of 1970. Deep-Sea Res. Oceanogr. Abstr., 19, 319-325, https://doi.org/10.1016/0011-7471(72)90025-3.

Li, C., and M. Yanai, 1996: The onset and interannual variability of the Asian summer monsoon in relation to land-sea thermal contrast. J. Climate, 9, 358-375, https://doi.org/10.1175/15200442(1996)009<0358:TOAIVO > 2.0.CO;2.

Li, S., J. Lu, G. Huang, and K. Hu, 2008: Tropical Indian Ocean basin warming and East Asian summer monsoon: A multiple AGCM study. J. Climate, 21, 6080-6088, https://doi.org/10.1175/ 2008JCLI2433.1.

Li, T., C. Tham, and C. Chang, 2001: A coupled air-sea-monsoon oscillator for the tropospheric biennial oscillation. J. Climate, 14, 752-764, https://doi.org/10.1175/1520-0442(2001)014<0752: ACASMO $>2.0 . \mathrm{CO} ; 2$.

Lighthill, M. J., 1969: Dynamic response of the Indian Ocean to onset of the southwest monsoon. Philos. Trans. Roy. Soc. London, A265, 45-92, https://doi.org/10.1098/rsta.1969.0040.

Liu, H., P. Lin, Y. Yu, and X. Zhang, 2012: The baseline evaluation of LASG/IAP climate system ocean model (LICOM) version 2. Acta Meteor. Sin., 26, 318-329.

—, Y. Yu, P. Lin, and F. Wang, 2014: High-resolution LICOM. Flexible Global Ocean-Atmosphere-Land System Model: A Modeling Tool for the Climate Change Research Community, T. Zhou et al., Eds., Springer, 321-331.

Liu, S., and A. Duan, 2017: Impacts of the leading modes of tropical Indian Ocean sea surface temperature anomaly on subseasonal evolution of the circulation and rainfall over East Asia during boreal spring and summer. J. Meteor. Res., 31, 171-186, https://doi.org/10.1007/s13351-016-6093-z.

Liu, Y., M. Lu, H. Yang, A. Duan, B. He, S. Yang, and G. Wu, 2020: Land-atmosphere-ocean coupling associated with the Tibetan Plateau and its climate impacts. Natl. Sci. Rev., 7, 534-552, https://doi.org/10.1093/nsr/nwaa011.

Mao, J., and G. Wu, 2007: Interannual variability in the onset of the summer monsoon over the eastern Bay of Bengal. Theor. Appl. Climatol., 89, 155-170, https://doi.org/10.1007/ s00704-006-0265-1.

Meehl, G. A., 1987: The annual cycle and interannual variability in the tropical Pacific and Indian Ocean regions. Mon. Wea. Rev., 115, 27-50, https://doi.org/10.1175/1520-0493(1987)115<0027: TACAIV $>2.0 . \mathrm{CO} ; 2$.

Meng, W., and G. Wu, 2000: Gearing between the Indo-monsoon circulation and the Pacific-Walker circulation and the ENSO. Part II: Numerical simulation. Chin. J. Atmos. Sci., 24,15-25, https://doi.org/10.3878/j.issn.1006-9895.2000.01.02.

Oleson, K., and Coauthors, 2004: Technical description of the Community Land Model (CLM). NCAR Tech. Note NCAR/ TN-461+STR, 173 pp., https://doi.org/10.5065/D6N877R0.
Paulson, C. A., and J. J. Simpson, 1977: Irradiance measurements in the upper ocean. J. Phys. Oceanogr., 7, 952-956, https://doi.org/ 10.1175/1520-0485(1977)007<0952:IMITUO > 2.0.CO;2.

Qiu, B., 2000: Interannual variability of the Kuroshio Extension system and its impact on the wintertime SST field. J. Phys. Oceanogr., 30, 1486-1502, https://doi.org/10.1175/1520-0485(2000) 030<1486:IVOTKE $>2.0 . \mathrm{CO} ; 2$.

Rao, K. G., and B. Goswami, 1988: Interannual variations of sea surface temperature over the Arabian Sea and the Indian monsoon: A new perspective. Mon. Wea. Rev., 116, 558-568, https://doi.org/ 10.1175/1520-0493(1988)116<0558:IVOSST>2.0.CO;2.

Rayner, N., and Coauthors, 2003: Global analyses of sea surface temperature, sea ice, and night marine air temperature since the late nineteenth century. J. Geophys. Res., 108, 4407, https:// doi.org/10.1029/2002JD002670.

Rodwell, M. J., and B. J. Hoskins, 1996: Monsoons and the dynamics of deserts. Quart. J. Roy. Meteor. Soc., 122, 1385-1404, https://doi.org/10.1002/qj.49712253408.

_ and - 2001: Subtropical anticyclones and summer monsoons. J. Climate, 14, 3192-3211, https://doi.org/10.1175/15200442(2001)014<3192:SAASM > 2.0.CO;2.

Rosati, A., and K. Miyakoda, 1988: A general circulation model for upper ocean simulation. J. Phys. Oceanogr., 18, 1601-1626, https:// doi.org/10.1175/1520-0485(1988)018<1601:AGCMFU>2.0.CO;2.

Schneider, T., T. Bischoff, and G. H. Haug, 2014: Migrations and dynamics of the intertropical convergence zone. Nature, $\mathbf{5 1 3}$, 45-53, https://doi.org/10.1038/nature13636.

Schott, F. A., S. P. Xie, and J. P. McCreary, 2009: Indian Ocean circulation and climate variability. Rev. Geophys., 47, RG1002, https://doi.org/10.1029/2007RG000245.

Wang, B., 2006: The Asian Monsoon. Springer, 787 pp.

_, Q. Ding, X. Fu, I.-S. Kang, K. Jin, J. Shukla, and F. DoblasReyes, 2005: Fundamental challenge in simulation and prediction of summer monsoon rainfall. Geophys. Res. Lett., 32, L15711, https://doi.org/10.1029/2005GL022734.

Wang, Z., A. Duan, and G. Wu, 2014: Time-lagged impact of spring sensible heat over the Tibetan Plateau on the summer rainfall anomaly in East China: Case studies using the WRF model. Climate Dyn., 42, 2885-2898, https://doi.org/10.1007/s00382013-1800-2.

,-- , and S. Yang, 2018: Potential regulation on the climatic effect of Tibetan Plateau heating by tropical air-sea coupling in regional models. Climate Dyn., 52, 1685-1694, https:// doi.org/10.1007/s00382-018-4218-z

Wen, Q., and H. Yang, 2020: Investigating the role of the Tibetan Plateau in the formation of Pacific meridional overturning circulation. J. Climate, 33, 3603-3617, https://doi.org/10.1175/ JCLI-D-19-0206.1.

Wu, B., T. Li, and T. Zhou, 2010: Relative contributions of the Indian Ocean and local SST anomalies to the maintenance of the western North Pacific anomalous anticyclone during the El Niño decaying summer. J. Climate, 23, 2974-2986, https:// doi.org/10.1175/2010JCLI3300.1.

Wu, G., 1984: The nonlinear response of the atmosphere to large-scale mechanical and thermal forcing. J. Atmos. Sci., 41, 2456-2476, https:// doi.org/10.1175/1520-0469(1984)041<2456:TNROTA>2.0.CO;2.

— , and Y. Liu, 2000: Thermal adaptation, overshooting, dispersion, and subtropical anticyclone. Part I: Thermal adaptation and overshooting. Chin. J. Atmos. Sci., 24, 433-446, https://doi.org/10.3878/j.issn.1006-9895.2000.04.01.

, and - 2003: Summertime quadruplet heating pattern in the subtropics and the associated atmospheric circulation. Geophys. Res. Lett., 30, 1201, https://doi.org/10.1029/2002GL016209. 
— H. Liu, Y. Zhao, and W. Li, 1996: A nine-layer atmospheric general circulation model and its performance. Adv. Atmos. Sci., 13, 1-18, https://doi.org/10.1007/BF02657024.

—, W. Li, H. Guo, and H. Liu, 1997: Sensible heat driven air-pump over the Tibetan Plateau and its impacts on the Asian summer monsoon. Collections in the Memory of Zhao Jiuzhang (in Chinese), D. Z. Ye et al., Eds., Chinese Science Press, 116-126.

_ , and Coauthors, 2007: The influence of mechanical and thermal forcing by the Tibetan Plateau on Asian climate. J. Hydrometeor., 8, 770-789, https://doi.org/10.1175/JHM609.1.

, Y. Liu, X. Zhu, W. Li, R. Ren, A. Duan, and X. Liang, 2009: Multi-scale forcing and the formation of subtropical desert and monsoon. Ann. Geophys., 27, 3631-3644, https://doi.org/ 10.5194/angeo-27-3631-2009.

$\longrightarrow,-$ B. He, Q. Bao, A. Duan, and F. F. Jin, 2012: Thermal controls on the Asian summer monsoon. Sci. Rep., 2, 404, https://doi.org/10.1038/srep00404.

_- and Coauthors, 2015: Tibetan Plateau climate dynamics: Recent research progress and outlook. Natl. Sci. Rev., 2, 100 116, https://doi.org/10.1093/nsr/nwu045.

—, H. Zhuo, Z. Wang, and Y. Liu, 2016: Two types of summertime heating over the Asian large-scale orography and excitation of potential-vorticity forcing. I. Over Tibetan Plateau. Sci. China Earth Sci., 59, 1996-2008, https://doi.org/ 10.1007/s11430-016-5328-2.

Xie, S.-P., H. Annamalai, F. A. Schott, and J. P. McCreary Jr., 2002: Structure and mechanisms of south Indian Ocean climate variability. J. Climate, 15, 864-878, https://doi.org/10.1175/ 1520-0442(2002)015<0864:SAMOSI >2.0.CO;2.

, K. Hu, J. Hafner, H. Tokinaga, Y. Du, G. Huang, and T. Sampe, 2009: Indian Ocean capacitor effect on Indo-western Pacific climate during the summer following El Niño. J. Climate, 22, 730-747, https://doi.org/10.1175/2008JCLI2544.1.
Yang, H., and Q. Wen, 2020: Investigating the role of the Tibetan Plateau in the formation of Atlantic meridional overturning circulation. J. Climate, 33, 3585-3601, https://doi.org/10.1175/ JCLI-D-19-0205.1.

Yang, J., Q. Liu, S. P. Xie, Z. Liu, and L. Wu, 2007: Impact of the Indian Ocean SST basin mode on the Asian summer monsoon. Geophys. Res. Lett., 34, L02708, https://doi.org/10.1029/ 2006 GL028571.

Ye, D., and Y. Gao, 1979: The Meteorology of the Qinghai-Xizang (Tibet) Plateau. Science Press, 278 pp.

, and G.-X. Wu, 1998: The role of the heat source of the Tibetan Plateau in the general circulation. Meteor. Atmos. Phys., 67, 181-198, https://doi.org/10.1007/BF01277509.

Yeh, T., 1950: The circulation of the high troposphere over China in the winter of 1945-46. Tellus, 2, 173-183, https://doi.org/ 10.3402/tellusa.v2i3.8548.

Zhao, P., and L. Chen, 2001: Interannual variability of atmospheric heat source/sink over the Qinghai-Xizang (Tibetan) Plateau and its relation to circulation. Adv. Atmos. Sci., 18, 106-116, https://doi.org/10.1007/s00376-001-0007-3.

— S. Yang, R. Wu, Z. Wen, J. Chen, and H. Wang, 2012: Asian origin of interannual variations of summer climate over the extratropical North Atlantic Ocean. J. Climate, 25, 6594-6609, https://doi.org/10.1175/JCLI-D-11-00617.1.

Zhao, Y., A. Duan, and G. Wu, 2018: Interannual variability of late-spring circulation and diabatic heating over the Tibetan Plateau associated with Indian Ocean forcing. Adv. Atmos. Sci., 35, 927-941, https://doi.org/10.1007/ s00376-018-7217-4.

,,$-- \ldots$, and R. Sun, 2019: Response of the Indian Ocean to the Tibetan Plateau thermal forcing in late spring. J. Climate, 32, 6917-6938, https://doi.org/10.1175/JCLI-D18-0880.1. 